\title{
Identidad étnica de preparatorianos universitarios indígenas en México ante las representaciones mediáticas de "lo indígena"
}

Ethnic identity and significance of indigenous cultures represented in the mass media by indigenous high school and university students

\section{Juan Antonio Doncel de la Colina}

\section{Q OpenEdition}

\section{Journals}

Electronic version

URL: http://journals.openedition.org/corpusarchivos/1553

DOI: $10.4000 /$ corpusarchivos. 1553

ISSN: 1853-8037

Publisher

Diego Escolar

\section{Electronic reference}

Juan Antonio Doncel de la Colina, «Identidad étnica de preparatorianos universitarios indígenas en

México ante las representaciones mediáticas de "lo indígena" », Corpus [En línea], Vol 6, No 1 | 2016,

Publicado el 28 junio 2016, consultado el 30 abril 2019. URL : http://journals.openedition.org/ corpusarchivos/1553; DOI : 10.4000/corpusarchivos.1553

This text was automatically generated on 30 April 2019.

Licencia Creative Commons: Atribución-NoComercial 2.5 Argentina (CC BY-NC 2.5 AR) 


\section{Identidad étnica de preparatorianos universitarios indígenas en México ante las representaciones mediáticas de "lo indígena"}

Ethnic identity and significance of indigenous cultures represented in the mass media by indigenous high school and university students

Juan Antonio Doncel de la Colina

\section{Introducción}

1 Nuevo León es un estado mexicano, ubicado al noreste del país y que colinda con Estados Unidos, en el que en su historia moderna no ha convivido un número significativo de pobladores considerados parte de los pueblos originarios, pues los grupos étnicos prehispánicos que habitaban la región eran grupos eminentemente nómadas que fueron prácticamente exterminados en el proceso de conquista. No obstante, Monterrey, capital del estado y destacado motor económico y financiero del país, constituye un poderoso polo de atracción para diversos tipos de migración de carácter económico (Doncel 2011). Entre estos tipos de migración está la de los indígenas mexicanos que buscan mejores oportunidades laborales y académicas. Hasta tal punto llega este poder de atracción que en los últimos quince años el crecimiento de este tipo de migración llegada al Área Metropolitana de Monterrey (AMM) fue del 165\%, convirtiendo a esta entidad en la principal receptora de población indígena en México ( $\left.\mathrm{CDI}^{1} 2011\right)$.

2 En enero de 2015 iniciamos desde el Centro de Estudios Interculturales del Noreste de la Universidad Regiomontana un ambicioso proyecto de investigación titulado "Estudiantes indígenas de Educación Media Superior y Superior en Nuevo León. Panorama de inserción socioeducativa y construcción de identidad étnica"2. Con este proyecto nos proponemos analizar los procesos de reconstrucción de la identidad étnica de aquellos indígenas 
asentados en el AMM, en su inmensa mayoría inmigrantes llegados de otros estados mexicanos, y que conforman una minoría (numérica) dentro de su propia minoría (étnica), pues representan a esos poquísimos migrantes e indígenas que logran romper el techo educativo impuesto por la posesión de un capital cultural tan ajeno al que marca la cultura mestiza dominante.

3 Cuando hablamos de minorías étnicas nos circunscribimos al enfoque aportado por Appadurai, el cual concibe a estas como recordatorios constantes a las mayorías, con las que tienen que convivir, de aquello que no quieren ser, lo que provoca reacciones de rechazo, exclusión y violencia (ya sea simbólica o material).

La extraña reciprocidad intrínseca de las categorías de "mayoría" y "minoría" en el pensamiento social liberal, la cual genera lo que he denominado angustia de lo incompleto. Las mayorías numéricas pueden convertirse en predatorias y etnocidas de los números pequeños precisamente cuando algunas minorías (y sus números pequeños) recuerdan a las mayorías la pequeña brecha que media entre su condición de mayorías y el horizonte de un todo nacional impoluto, de una etnia nacional pura y sin tacha. Esta sensación de lo incompleto puede llevar a las mayorías a un paroxismo de violencia contra las minorías (Appadurai 2007, p. 22)

Esta "angustia de lo incompleto" se entiende con especial claridad cuando nos referimos a la actitud generalizada de ese sector de la población que en México denominamos como mestizos $^{3}$ y opuesto a lo que entendemos por indígena ${ }^{4}$. Por supuesto que esta cultura mestiza no es una, sino que son tantas y tan diversas como lo es la geografía y la estratificación social mexicanas, pero no nos proponemos aquí dar cuenta de la complejidad que caracteriza a la contraparte de nuestro universo de estudio ${ }^{5}$. Lo que sí es importante resaltar es precisamente esta oposición entre lo mestizo y lo indígena, pues de ninguna manera aquel se puede entender sin este, aunque sea por la forma en que nos definimos a través de lo que rechazamos (Douglas 1998). Como ya hemos comprobado en anteriores estudios (Doncel 2013), la percepción del joven nuevoleonés hacia lo "indígena" se caracteriza por la contradicción interna, por la percepción del indígena actual como pobre, analfabeto y atrasado frente al indígena histórico como origen de la identidad nacional y de la cultura con mayúsculas. Asimismo, encontramos que los valores de estos jóvenes se mueven entre el ideal de progreso (que representan los europeos $\mathrm{y}$, sobre todo, los estadounidenses) y lo que conciben como materialización del atraso en los pueblos indígenas. Esto llama poderosamente la atención, siendo que la mayor parte de ellos históricamente provienen de la mezcla entre españoles e indígenas, en mayor o menor grado. De este modo, podemos pensar que el rechazo del indígena es un rechazo a ellos mismos, a esa parte que no quieren reconocer como propia porque les recuerda aquello de lo que quieren escapar; aunque inevitablemente la identidad se construye también a partir de lo que se rechaza. Como expone Hall "las identidades se construyen a través de la diferencia, no al margen de ella (...) La unidad, la homogeneidad interna que el término identidad trata como fundacional, no es una forma natural sino construida de cierre, y toda identidad nombra como su otro necesario, aunque silenciado y tácito, aquello que le 'falta"' (Hall 2011, pp. 18-19).

5 Así, encontramos en el mexicano un consustancial conflicto identitario, pues ese "todo nacional impoluto" al que se refiere Appadurai en este caso aparece como "contaminado" desde el origen. Frente al histórico esfuerzo esencializador de todas las instituciones del Estado y de los más diversos agentes socializadores para la construcción de una identidad nacional, encontramos en la actualidad de las ciencias sociales una postura dominante marcada por el constructivismo. Según esta postura, los límites nacionales que nos 
separan son concebidos como artificiales, contingentes y cambiantes (Fernández de Rota 2005), llegando a dudar, como hace el propio Appadurai, del futuro cada vez más incierto de los Estados-nación y de las soberanías nacionales.

6 Si la identidad nacional mexicana está en constante tensión, la identidad nacional del indígena mexicano debe afrontar otro tipo de contradicciones. Veremos en este trabajo, de manera tangencial y con la expectativa de abrir caminos para posteriores exploraciones discursivas, algunos destellos de estos conflictos referidos a la identidad nacional de los migrantes indígenas que forman parte de nuestro universo. No obstante, el centro de nuestra atención aquí radica en la construcción de la identidad étnica. En este sentido, consideramos que continúa vigente la perspectiva del enfoque propuesto por Barth (1976), según el cual "la etnia es ante todo una categoría de adscripción cuya continuidad depende del mantenimiento de una frontera y por lo tanto de una codificación constantemente renovada de las diferencias culturales entre grupos vecinos" (Pierre Bonte 1996, p. 258). Esto implicaría, en tiempos de la globalización y del masivo éxodo rural de los jóvenes indígenas hacia las ciudades, una inevitable transformación de la identidad étnica, en la medida en la que los contactos interétnicos se dan, cada vez más, a un nivel individualizante y no tanto como contacto entre colectividades.

7 Cuestión y dinámicas aparte son las reacciones que suscitan a nivel endogrupal aquellos que, siendo numéricamente inferiores en el seno de su propia comunidad, ostentan un estatus socioeconómico y un capital cultural que les ubica en una ambigua posición social desde el punto de vista de la propia comunidad; pues son y no son, pertenecen sin pertenecer, empezando a resultar, en muchos sentidos, extraños ante los suyos ${ }^{6}$. Así, el conflicto o tensión de identidades móviles que plantea Appadurai (2007) entre las identidades de origen, las de residencia y las de aspiración, si en el caso del migrante e indígena son evidentes, en el caso del migrante indígena con estudios superiores adquiere un mayor nivel de complejidad. Aquí el factor educativo es introducido como elemento que habrá de jugar un papel decisivo en sus procesos de (re)construcción de identidades.

ante esta compleja problemática socioantropológica, decidimos plantear un amplio proyecto de investigación para analizar el proceso de reconfiguración identitaria que hipotéticamente viven estos estudiantes o egresados de Educación Media Superior y/ o Superior. Para ello consideramos cinco esenciales agentes socializadores, entendidos como dimensiones que nos ayuden a explicar el fenómeno. Estos agentes socializadores son los que representan el ámbito familiar, el comunitario, el escolar, el laboral y el ámbito de los medios de comunicación de masas.

9 Damos aquí continuidad al artículo en el que presentamos los primeros resultados referidos a la influencia que los medios de comunicación de masas tienen en la construcción de la identidad étnica de estos estudiantes indígenas. Si bien comenzamos profundizando tanto en los usos como en las significaciones, diferenciadas respecto a los mestizos, que estos estudiantes dan a ciertos medios de comunicación (Doncel, en prensa), ahora ofrecemos un análisis de cómo son interpretadas y significadas por los protagonistas de nuestra investigación las representaciones que los medios de comunicación elaboran de las que ellos mismos consideran culturas indígenas mexicanas.

10 El análisis de estas interpretaciones y significaciones sentarán las bases que nos ayuden a dar cuenta de los procesos de identificación (o desidentificación) de los estudiantes indígenas con las representaciones mediáticas consumidas por los mismos y, finalmente, en posteriores trabajos, con la (re)construcción de su identidad étnica. En este punto y antes de explicar el diseño metodológico de nuestra investigación, es importante precisar 
que tal diseño está orientado a la comprensión de estos procesos desde un punto de vista colectivo, más que personal ${ }^{7}$. Basándonos en el trabajo de campo realizado (principalmente de entrevistas semidirigidas), lo que pretendemos es mostrar este proceso con múltiples casos, pero que muestran ciertas pautas en común para este sector de la población.

El planteamiento metodológico de nuestro proyecto es, en su primera etapa, totalmente cualitativo. Para el análisis de nuestros hallazgos partimos de los datos obtenidos, por un lado, de diversas observaciones participantes en eventos de asociaciones civiles para estudiantes indígenas y espacios urbanos donde concurre esta población y, por otra parte $\mathrm{y}$ sobre todo, de las entrevistas semidirigidas realizadas a veintinueve estudiantes indígenas de Educación Media Superior y Superior en el AMM.

Aunque las observaciones aportaron datos significativos que ayudaron a complementar, desde el plano de la práctica social, la información obtenida a partir de las entrevistas para el desarrollo de temáticas como el uso de ciertos medios de comunicación ${ }^{8}$, en este caso nos apoyamos totalmente en la información obtenida a partir de las entrevistas. Al poner ahora, exclusivamente, nuestro foco de atención en los discursos acerca de la valoración y percepción subjetiva (o intersubjetiva) de ciertas representaciones mediáticas, el plano de la práctica social no ha sido relevante para nuestro análisis (y, en consecuencia, los datos obtenidos de la observación participante no han sido considerados para analizar las temáticas específicas que ofrecemos en este pequeño tramo de nuestra investigación).

Las entrevistas fueron realizadas por estudiantes de la Licenciatura en Comunicación, de la Universidad Regiomontana (U-ERRE), concretamente a través de la materia Análisis Cualitativo en Comunicación. Tras la capacitación pertinente a los alumnos regiomontanos que ocupan un estatus socioeconómico acomodado (lo suficientemente acomodado para poder pagar la colegiatura de esta costosa universidad privada), se organizó, a través de la asociación civil Zihuame Mochilla, un encuentro entre estos alumnos y estudiantes indígenas de preparatoria o universidad becados por la asociación. El convivio, organizado por los estudiantes de la U-ERRE y realizado con la finalidad de que tuviesen un contacto previo a la realización de la entrevista, supuso el encuentro de dos sectores poblacionales con algunos puntos en común como la edad, el nivel educativo y la ciudad en la que viven, pero muchos más puntos divergentes, como el estatus socioeconómico, el origen étnico, el capital cultural, el lugar de nacimiento, la lengua materna, etc. Este primer encuentro fue esencial para el buen desarrollo de las posteriores entrevistas, pues se pudieron relacionar, en un ambiente de total igualdad y respeto, jóvenes provenientes de mundos totalmente ajenos (para la mayor parte de los estudiantes de la U-ERRE era la primera vez en su vida que se relacionaban con una persona indígena). Una vez establecida la dinámica social del evento, se dejó libertad a cada estudiante-investigador para relacionarse con su contraparte y, en función de los criterios de cada uno, contactar con la persona a la que posteriormente entrevistará (criterios personales, pero siempre respetando en último término los criterios preestablecidos para la selección de la muestra, que vamos a explicar más adelante).

14 Así pues, a partir de este encuentro cada estudiante de la U-ERRE contactó con, por lo menos, un estudiante indígena para realizarle la entrevista y, mediante la técnica de la bola de nieve, acceder a otros dos estudiantes para completar las entrevistas que le fueron asignadas. Los lugares y condiciones de las entrevistas fueron variados, pero en todos los casos se tuvo especial cuidado de que se desarrollasen en espacios "neutrales", 
tranquilos y aptos para generar el necesario clima de confianza. En este sentido, a pesar de que, a fin de respetar el principio de anonimato, mantendremos el término "informante" para referirnos a las personas entrevistadas que forman parte de nuestro universo de estudio, realmente durante el trabajo de campo superamos en gran medida la tradicional asimetría entre investigador e investigado, pues la comunicación y la información que se dio entre ambos fluyó en ambos sentidos. La conveniencia de fomentar este flujo bidireccional de la comunicación fue una directriz explicitada a los entrevistadores durante su previa capacitación, dándoles instrucción de que, tanto en el convivio previo como durante las entrevistas, no se limitaran a realizar preguntas al entrevistado, sino que conversaran con ellos y que les facilitaran información, tanto personal como del proyecto o de la universidad. Se trataba con esto de huir de un modelo de entrevista con aspecto de interrogatorio y que implica una imposición unilateral del poder del entrevistador.

Respecto a la delimitación de nuestro universo de estudio, hemos considerado que todos los sujetos deben cumplir con los siguientes criterios: haber cursado, por lo menos, un semestre completo de alguno de los dos niveles educativos considerados (a fin de que haya tenido tiempo de interiorizar mínimamente su proceso de adaptación escolar); que haya estudiado en un centro educativo ubicado en el Área Metropolitana de Monterrey (área en la que se concentra más del $90 \%$ de la población del estado); que haya emigrado desde una comunidad indígena (para que se pueda dar un auténtico proceso de reconstrucción de la identidad étnica).

Este último criterio, el de ser migrante, unido al de provenir de un ámbito rural, ha tenido especial relevancia durante nuestro trabajo de campo. Dado el extendido estigma que existe en la población de acogida respecto hacia el indígena, el propio término "indígena" se convirtió en un problema para el diseño del guion de la entrevista. Considerando los procesos de autoocultamiento étnico, así como la aceptación e interiorización de este estigma por parte de ciertos estudiantes indígenas, debimos reflexionar profundamente, antes de la realización de las entrevistas, con qué término nos íbamos a dirigir a ellos. Esto en atención a que muchos no se reconocen ante el extraño ni como indígenas, ni como miembros de un grupo étnico. La solución que encontramos fue dar opciones en el guion de la entrevista al uso de varios términos, a fin de que el propio entrevistador decidiera, en función de las características del entrevistado, qué término debía utilizar en este momento (pues, por ejemplo, frente al problema del autoocultamiento también hay cierta tendencia entre los universitarios y activistas en defensa de los derechos de los pueblos indígenas a asumirse y reivindicarse con orgullo bajo este término). Así, el entrevistador podría referirse en sus preguntas al término indígena o miembro de un grupo étnico (especificando el correspondiente en cada caso) o miembro de una comunidad o, incluso, foráneo o "ser de fuera".

17 Son muchas las coincidencias entre inmigrantes indígenas e inmigrantes que no lo son, sobre todo, como decimos, si provienen del ámbito rural (a la problemática común de la migración se une la concepción propia de este ámbito de socialización). En estos casos, la lógica de las diferentes formas de vida social en el medio rural hace que la coincidencia en las respuestas sea, presumiblemente, grande (por ejemplo, en cierta valoración de la naturaleza, cierta forma de interactuar socialmente o la nostalgia de lo local, opuesta al gusto por lo global). No obstante, aun en los casos en los que se da un aparente rechazo a la propia identidad étnica, las diferencias entre los habitantes de lo rural "no indígenas" e 
indígenas son más que suficientes para trazar una clara línea separadora para nuestro análisis.

En la base de esta cohesión interna (y de la consecuente diferencia respecto a la dimensión exogrupal), aparece el hecho de compartir una lengua diferente al español. En este sentido, respecto al problema de la lengua, también debimos hacer un ajuste metodológico en el diseño de nuestras entrevistas. Para ser considerados indígenas, desde un enfoque inicialmente etic, establecimos la necesidad de que nuestros entrevistados hablen o que procedan de una familia o comunidad que habla alguna de las 68 lenguas indígenas que se usan en la república mexicana. Es decir, el factor lingüístico es el que instrumentalizamos para la delimitación del concepto de etnicidad. También sobre etnicidad y lengua reflexionaremos en nuestra fundamentación teórica, pero aquí debemos hacer esta precisión metodológica.

Es bien sabido por los estudiosos de la cuestión indígena en México que estas 68 lenguas, procedentes de 11 familias lingüísticas, en la vida cotidiana son minusvaloradas y degradadas con el término "dialecto", el cual es usualmente considerado como una simple vertiente o ramificación de una lengua con su propia gramática. El estigma del indígena en México y la infravaloración de muchos de sus valores y prácticas culturales encuentran un firme aliado en el uso del término dialéctico al referirse a sus lenguas ${ }^{9}$. Siendo plenamente conscientes de esta situación, pero considerando que muchos de los entrevistados entienden que ellos hablan un dialéctico y no una lengua, tomamos, en aras de la eficacia comunicativa, una polémica decisión (en una línea similar a la que acabamos de explicar respecto al término "indígena"): le dimos al entrevistador la opción de que eligiese, en función de las características particulares de cada entrevistado, entre usar el término lengua, idioma o dialecto. Es por esta razón por la que en algunos fragmentos de las entrevistas encontraremos uno $u$ otro término utilizado, aparentemente, de forma indistinta.

Una vez delimitado nuestro universo de estudio, seleccionamos una muestra caracterizada por una importante diversidad en lo que se refiere a la situación escolar (en proceso, egresado o trunco), al género, al tipo de institución educativa (pública o privada), al origen y al grupo étnico de pertenencia. Respecto a esta última variable, como podemos apreciar en el gráfico $n^{\circ} 1$, los entrevistados de etnia náhuatl y tének aparecen aparentemente sobrerrepresentados. Pero esta sobrerrepresentación es solo aparente como comprobamos si nos fijamos en la distribución por grupos étnicos de los indígenas que habitan en el estado de Nuevo León (tabla $n^{\circ} 1$ ).

21 Por otra parte, no debemos perder de perspectiva que estamos realizando un estudio cualitativo, por lo que la muestra busca ser significativa y no tanto representativa del universo del que se extrae. Además, es importante señalar que la variable "origen étnico" no ha resultado ser explicativa de una respuesta u otra hacia la representación percibida del indígena y sus culturas en los medios de comunicación de masas.

Como expone Giddens (1993), es la intersubjetividad, junto con la actividad humana, la materia que alimenta a las ciencias sociales (Doncel 2012a). Es decir, en aquellas es en las que los científicos sociales deben centrar su atención y subordinar su enfoque metodológico. De las veintinueve entrevistas realizadas se ha organizado en tablas comparativas la información cualitativa, con el fin de encontrar en todas las respuestas obtenidas a ciertas preguntas esta matriz de intersubjetividad. Es decir, como apuntábamos más arriba, por el momento no estamos explorando procesos de un orden más íntimo o psicológico, sino procesos colectivos de un determinado sector poblacional 
con ciertas características identitarias en común. Es por ello que no especificamos en profundidad las circunstancias vitales y características personales de cada uno de nuestros informantes, cosa que sí haremos, obviamente, cuando exploremos en posteriores trabajos estos procesos personales a través de historias de vida.

No obstante, en nuestro trabajo hay dos informantes que creemos que simbolizan dos posiciones típico-ideales de todos los demás, como veremos en las conclusiones: la de la adolescente estudiante de preparatoria, negadora en alto grado de su identidad étnica y que no consume medios que reflejen su cultura originaria; frente a la joven estudiante de posgrado, con una conciencia clara de su identidad étnica, con su pueblo y consumidora de productos mediáticos reforzadores de esta identidad. Siendo estas dos informantes las que emiten testimonios que aparecen en este artículo con mayor reiteración, consideramos que se justifica contextualizar y describir un poco más detalladamente sus circunstancias vitales.

La que denominamos "informante 1" se trata de una joven adolescente de 17 años estudiante de segundo semestre, en turno matutino, de una preparatoria general adscrita a la Universidad Autónoma de Nuevo León. Ella proviene de una comunidad de la Huasteca Potosina y habla tének, principalmente con su familia y únicamente cuando está en su comunidad. Además de estudiar, trabaja de niñera y vive en la casa de la madre del niño que cuida. Por otra parte, nuestra informante 14, es una joven de 26 años, licenciada de Psicología y estudiante de una maestría de Educación, en turno nocturno, en una universidad privada gracias a una beca de estudios. Antes de estar becada trabajó durante muchos años como empleada doméstica en la misma casa en la que vivía (parece que el apoyo de su jefa fue crucial para el éxito obtenido en los estudios). Proviene de una pequeña comunidad de la Huasteca Potosina y habla tének, con su familia y con todo aquel que lo entienda.

Establecido el planteamiento general de nuestra propuesta, pasamos ahora a desarrollar el contenido del artículo propiamente dicho, el cual comienza con el establecimiento de las bases teóricas sobre las que se asientan los resultados empíricos obtenidos. Tras el debate teórico reflexionamos en torno al estado de la cuestión, aportando algunos estudios previos que han considerado la problemática de los medios de comunicación de masas y la construcción (o reconstrucción) de las identidades étnicas entre los pueblos originarios del continente americano. Tras esta aproximación a nuestro objeto de estudio ofrecemos los resultados de nuestra propia investigación, resultados que se entregan en dos bloques temáticos: el referido a la presencia y valoración de las lenguas indígenas en los medios de comunicación y la significación que los entrevistados elaboran de la representación de sus expresiones y prácticas culturales en estos medios de comunicación.

\section{Fundamentación teórica}

En lo que se refiere al protagonismo que otorgamos al análisis del consumo y valoración de las diferentes lenguas indígenas emitidas por los medios de comunicación de masas, partimos de la histórica preocupación por la relación que existe entre la construcción del lenguaje y la realidad social y cultural del sujeto.

27 La hipótesis de Sapir-Whorf, contextualizada en el marco de la lingüística estructural en la que se apoyaron posteriormente algunos representantes de la Escuela de Chicago, 
establece el principio del determinismo lingüístico (la lengua determina el pensamiento) y el principio de la relatividad lingüística (los individuos organizan el mundo sensible, externo a ellos, a partir de la codificación que permite la estructura de una lengua específica). Muy influenciados por el maestro de Sapir, Franz Boas, y el relativismo cultural, según estos autores nuestra interpretación de la realidad está determinada de manera tajante por el lenguaje, siendo este definido culturalmente y provocando una interpretación distintiva de la realidad al centrar nuestra atención en ciertos fenómenos (Sapir 1929). Los críticos a esta teoría arguyen que no se puede admitir la idea de que una lengua que carezca de cierta palabra sea incapaz de expresar un concepto o que sus hablantes no lo puedan adquirir; así como se resisten a la imposibilidad de una comprensión absoluta translingüística (Moreno 2012).

Más adelante, Schaff (1975), quien transitó del marxismo más ortodoxo de la Europa Oriental de posguerra hacia las corrientes de la fenomenología y el existencialismos de los años 60, propone el planteamiento inverso: que la lengua es un producto de la práctica social. Es decir, que esta es la que determina la visión que cierta sociedad tiene de su propio mundo. Se trata de un visión menos determinista que la de Sapir y Whorf, pues, más bien propone una explicación dialéctica entre lengua y realidad, siendo aquella tanto reflejo como creadora de esta. Por último, como expone Moreno:

Durante los últimos años, la psicología cognitiva ha desarrollado otra propuesta teórica, preocupada también por la relación entre lengua, pensamiento y realidad (...): la teoría de los prototipos (...) La teoría de los prototipos propone que un concepto concreto se defina como un prototipo o caso típico de ese concepto: un prototipo sería el ejemplar idóneo, el mejor representante o el caso central de una categoría (Moreno 2012, p.193)

Consideramos que esta propuesta se adecúa mejor a la realidad intercultural a la que nos aboca esta época de globalización, además de favorecer la posibilidad de una explicación universal que el excesivo relativismo de la hipótesis Sapir-Whorf no permitiría. En esta misma línea de argumentación encontramos la propuesta de Palmer (2000), representante de una línea cognitivista que trata de ofrecer una explicación holística de los fenómenos de la cultura asociados a la imaginería lingüística convencionalizada. Según Palmer, el hecho de que las diferentes lenguas compartan estos prototipos hace que estas sean más parecidas de lo que aparentan. En todo caso y más allá del lugar común de las lenguas o de la dirección de la relación entre lengua y cultura, es claro que la variable lingüística ha de ser considerada en un estudio que pretende analizar el impacto de la representación cultural del grupo de referencia en los medios de comunicación sobre la propia identidad étnica. En este sentido, veremos, por ejemplo, cómo el análisis semiótico que un entrevistado realiza de su propia lengua (para justificar la imposibilidad o, cuando menos, la dificultad de que sea difundida su lengua en los medios masivos de comunicación) correlaciona claramente con una sólida identidad étnica.

Aceptada la importancia trascendental del lenguaje para la elaboración cultural, dado que desde él (o hacia él) estructuramos nuestro mundo social y cultural y vehiculamos nuestra interpretación de nuestro contexto, nos proponemos en un primer momento sondear qué tan presentes están las lenguas maternas de nuestros entrevistados en los diversos medios de comunicación que ellos utilizan y qué influencia tiene el consumo de estas lenguas en su propia conformación identitaria. Como ya señalamos en la introducción, tras la atención prestada a la variable lingüística, nos dedicaremos a explicar la forma en la que el estudiante indígena interioriza, valora y significa la imagen que los medios de 
comunicación están proyectando de sus expresiones culturales y, en definitiva, de sí mismos.

Dada la importancia otorgada a los procesos de significación intersubjetiva de ciertos productos mediáticos muy vinculados a la construcción de la propia identidad, no es de extrañar que recurramos en nuestra propuesta a algunas de las nociones propias del interaccionismo simbólico, así como de la antropología simbólica, corriente surgida en los años 60 para superar el estructural-funcionalismo británico y el evolucionismo norteamericano (Ortner, 1984). En lo que a esta corriente se refiere, para nosotros es determinante la concepción que Geertz tiene de la ciencia de la cultura entendida como ciencia interpretativa y no explicativa, ciencia que solo podrá alcanzar sus objetivos a través de lo denominada descripción densa (Geertz 2005). Así pues, pretendemos trascender una descripción superficial y dar cuenta de los significados que los propios actores dan, en este caso, a los mensajes emitidos por los medios masivos de comunicación ${ }^{10}$. De este modo, en la entrega de resultados, podremos comprobar cómo un mismo hecho (por ejemplo, la presencia de una representación cultural en los medios) y una misma actitud (el rechazo al consumo de estos productos mediáticos) son significadas por los sujetos de formas diversas, en función de las diferentes situaciones del contexto social, cultural y personal. Asimismo, veremos cómo, más allá del producto mediático, es el propio medio de comunicación el que adquiere una variedad de significados (como es el caso de la radio).

En este sentido, la mencionada teoría de los prototipos también parece adecuarse a este enfoque geertziano, pues los prototipos "dejan un lugar para las interpretaciones particulares de la realidad, dado que los límites entre unos conceptos y objetos de la vida real y otros son difusos: los individuos o los grupos sociales disfrutan de cierta libertad para aplicar e interpretar los conceptos de una forma particular" (Moreno 2012, p. 193).

Por su parte, en el interaccionismo simbólico encontramos una corriente que se desenvuelve en el paradigma interpretativo y que alimentó en igual medida a la sociología (desde su dimensión de análisis microsociológica), a la antropología social y a la psicología social. Uno de sus máximos exponentes, G. H. Mead, circunscrito en gran medida al paradigma conductista de los años 20 , amplía el espectro que tradicionalmente había cubierto la psicología, atendiendo a la importancia de la dimensión de la sociedad para explicar la construcción de la identidad:

Por lo general, la psicología social ha encarado varias fases de la experiencia social desde el punto de vista psicológico de la experiencia individual. La forma de enfoque que yo sugiero es la de tratar la experiencia desde el punto de vista de la sociedad, por lo menos desde el punto de vista de la comunicación en cuanto esencial para el orden social. La psicología social, en este sentido, presupone un ángulo de enfoque de la experiencia tomado desde el punto de vista del individuo, pero se propone determinar, en particular, qué pertenece a esa experiencia en razón de que el individuo mismo pertenece a una estructura social, a un orden social (Mead 1973, p. 49)

34 Aunque este ya clásico estudio de Mead nos permite una primera aproximación, consideramos que debemos ir más allá de este enfoque dialéctico, cuyos polos son el individuo y la sociedad. Bauman (2011 p. 40), reflexionando sobre el trabajo de Douglas Kellner acerca de su concepción goffmaniana de la identidad entendida como una libre presentación teatral del yo (y, por tanto, contingente) que impide, paradójicamente, satisfacer la percibida como necesaria reconstrucción de la identidad estable y unitaria, considera que en esta idea se sintetiza la ambivalencia actual de la cuestión de la 
identidad. Según Bauman lo que en la modernidad se constituía como problema de la identidad era la preocupación por su construcción y mantenimiento como sólida y estable, mientras que en la posmodernidad la problemática ha pasado a radicar en la evitación de la fijación ("para poder mantener vigentes las opciones").

Para explicar cómo se construye la identidad del sujeto, consideramos que en tiempos de la globalización este proceso debe ser abordado desde un enfoque procesual, más centrado en el discurso, tal y como plantean autores como Foucault (1968) y, partiendo del anterior, Hall, uno de los principales representante de los estudios culturales hoggartianos: "coincido con Foucault en que no necesitamos aquí 'una teoría del sujeto cognoscente', sino una teoría de la práctica discursiva” (Hall 2011, p. 14). No obstante, esto no supone una necesaria abolición del sujeto, sino una rearticulación entre el sujeto y sus prácticas discursivas. En este sentido, Hall hace hincapié en el debate surgido desde la teoría crítica para la superación de la noción de una identidad "integral, originaria y unificada" hacia un "yo incesantemente performativo" (p. 13).

Son numerosos los ejemplos extraídos de las entrevistas realizadas que nos mostrarán cómo a través del discurso el propio sujeto va construyendo su propia identidad étnica, desde los que desarrollan y consolidan una cierta negación de la misma hasta los que su propio discurso les ayuda a consolidarla, pasando por los que la reflexionan junto al entrevistador y, en consecuencia la relativizan. Asimismo, la construcción procesual de la identidad, más allá del discurso del sujeto, la observamos con claridad a través de la que será una de nuestras ideas centrales, emanadas del análisis empírico: el papel clave de la educación superior para que los sujetos pasen del ocultamiento y/o la falta de elaboración cognitiva de una identidad étnica (muy presentes en los preparatorianos), hacia un proceso de revalorización, criticismo y fortalecimiento de la identidad (más propio de los universitarios entrevistados).

En tiempos de la globalización, desde esta concepción procesual de la identidad se subraya la importancia de la lengua y la cultura, pero en el sentido de proyección futura, más que en el substrato pasado en común. Asimismo, la representación del yo colectivo se convierte en un elemento definitivo en este proceso identitario, enfoque eminentemente comunicativo que de nuevo nos conecta con postulados del interaccionismo simbólico y que, además, adquiere especial relevancia para un estudio con el objetivo declarado de contrastar representaciones mediáticas de un grupo humano con sus procesos colectivos de construcción de identidades.

Aunque [los debates sobre la identidad] parecen invocar un origen en un pasado histórico con el cual continúan en correspondencia, en realidad las identidades tienen que ver con las cuestiones referidas al uso de los recursos de la historia, la lengua y la cultura en el proceso de devenir y no de ser; no 'quienes somos' o 'de dónde venimos' sino en qué podríamos convertirnos, cómo nos han representado y cómo atañe ello al modo como podríamos representarnos. Las identidades, en consecuencia, se constituyen dentro de la representación y no fuera de ella. Se relacionan tanto con la invención de la tradición como con la tradición misma (Hall 2011, pp. 17-18)

Esta crítica antiesencialista de las concepciones étnicas, raciales y nacionales de la identidad cultural, posición según la cual "el enfoque discursivo ve la identificación como una construcción, un proceso nunca terminado: siempre 'en proceso"' (Hall 2011, p. 15), no debería ser óbice para considerar que las identidades étnicas perviven a las situaciones, cada vez más numerosas y complejas, de contacto interétnico (Barth 1976). Pero lo que actualmente permanece de estas identidades étnicas está en permanente 
tensión con el sentido de disolución. Como afirma el británico Peter Burke, especialista en historia de la cultura, "hemos 'deconstruido', es decir, asumido, la irrealidad de entidades como las naciones, las clases sociales y las castas (...) No existen fronteras culturales cerradas en sentido estricto, lo que hay es una especie de continuidad cultural" (Burke 2010, p. 64). Y de entre los miembros de los grupos étnicos que nos ocupan en este trabajo, son precisamente los jóvenes y, más aún, los jóvenes con estudios superiores, los que representan la punta de lanza en este proceso de cambio social, cultural e identitario; pues son ellos los que se encuentran más expuestos, transitando los límites de mundos socioculturales en contacto cotidiano, pero muy alejados en muchos sentidos.

No es, pues, de extrañar, que cada vez sean más los trabajos que desde el ámbito de la academia ponen de manifiesto una realidad cada vez más alejada del estereotipo del indígena en México (Durin 2010). Por ejemplo, Rivermar (2010) demuestra cómo xoyocatecos no son ya campesinos, ni en México ni en las ciudades estadounidenses a las que migran, al igual que sucede con los indígenas que viven en la Ciudad de México, pues más de la mitad de ellos han nacido ahí mismo y sólo un $6.3 \%$ se dedican a la venta ambulante (Molina 2010).

Por nuestra parte, a lo largo de nuestro trabajo surgirá naturalmente, del discurso de nuestros entrevistados, esta dicotomía entre la pervivencia de "lo indígena" y el "nuevo indígena". Encontraremos los que consumen medios con su idioma y los que no lo hacen (unos porque no los conocen, otros porque los rehúyen y otros en señal de protesta). Encontraremos los que critican la folclorización del indígena en los medios de comunicación de masas y los que trascienden la propia identidad a partir de su conciencia étnica abrazando una identidad indígena panamericana (lo que suele ir acompañado de un notable proceso de politización del sujeto). Encontraremos aquellos cuyos hábitos de reproducción cultural o idiomática son consecuencia de su actividad laboral y los que se implican social, cultural y políticamente a pesar de sus obligaciones laborales. Encontraremos los que se congratulan de ser representados en los medios por orgullo de lo propio, por el reconocimiento social que significa o por su valor ejemplarizante, y quienes lo critican por poner el acento en el papel discriminador, vejatorio o victimizador de estos medios. Por último, veremos cómo en un mismo sujeto se da, ante las diversas representaciones mediáticas del indígena, un abanico de emociones que van desde las más satisfactorias hasta las más desagradables. En suma, encontraremos multitud de respuestas que nos darán buena cuenta de la heterogeneidad y de las innumerables posibilidades que se dan entre la tendencia a la pervivencia de cierta forma tradicionalista de entender la etnicidad y las que insertan a esta nueva etnicidad en la posmodernidad, reinventándola.

41 Si bien parece que la globalización genera una fuerza centrífuga que empuja hacia una suerte de disolución identitaria, no es menos cierta la existencia de una fuerza centrípeta que refuerza (precisamente por el miedo a la disolución) el autorreconocimiento y las identidades étnicas o nacionales. En este contexto, la definición del término indígena se vuelve un reto cada vez más complejo. Por ejemplo, el que fuera director del Instituto Mexicano de Antropología e Historia (INAH), Guillermo Bonfil (1972), enumera una serie de criterios que históricamente han ido siendo superados para la definición del indio (que el autor considera sinónimo del término indígena): los criterios biológicos (por el problema que supone el mestizaje tan diverso en América); lingüísticos (arguyendo que en numerosas poblaciones, como la paraguaya y la lengua guaraní, muchos hablan una lengua indígena pero muy pocos son considerados como tales, así como hay muchos que 
no hablan su idioma pero sí son indígenas, lo que vemos con creciente frecuencia entre los jóvenes emigrados a la ciudad en México; es decir, no lo son todos los que hablan un idioma prehispánico, ni hablan un idioma prehispánico todos los que lo son), culturales (pues tradicionalmente se ha definido la "cultura indígena" por oposición a la "cultura occidental", sin preocuparse por el diverso contenido de sus culturas), de autoadscripción (pues dada la enorme diversidad de sociedades y culturas en América, no se puede unificar cabalmente el término para todos estos millones de pobladores).

Esta indefinición de lo indígena genera un problema con dos vertientes: la académica y la política. Respecto a la primera, al centrarnos específicamente en los jóvenes provenientes de una comunidad indígena, nos decidimos por delimitar nuestro universo desde un punto de vista totalmente pragmático. La razón de ser de esta decisión obedece a la subordinación de la delimitación de nuestro universo de estudio al objetivo de la investigación. Este es la solución que propone Carrasco, una solución relativizante y pragmática:

Pedro Carrasco, por ejemplo, señalaba dos alternativas: o se trataba de una definición arbitraria, escogida por el investigador en función del problema específico que desea estudiar -y por lo tanto, de valor sólo en términos de esa investigación particular-, o se reconocía que el indio es una categoría social peculiar de ciertos sistemas sociales y se estudiaba objetivamente en cada uno de ellos, sin pretender darle a esa categoría un rango más amplio que el que tenga en la sociedad concreta de que se trate (Carrasco citado por Bonfil 1972, pp. 108-109)

En el plano político, el auge de las políticas indigenistas dado a mediados del siglo pasado obligó cada vez con más fuerza a delimitar quién es sujeto de derecho. Es en este contexto que comienza a ser definido el indígena como minoría étnica, es decir, se comienza a definir por su depauperada situación en la estructura social. Así concluye el propio Bonfil, convirtiendo esta condición en estructural desde el inicio de la "creación" del indígena, con la llegada de los europeos a América.

De lo expuesto anteriormente se concluye que la definición de indio no puede basarse en el análisis de las particularidades propias de cada grupo (...) La categoría de indio, en efecto, es una categoría supraétnica que no denota ningún contenido específico de los grupos que abarca, sino una particular relación entre ellos y otros sectores del sistema social global del que los indios forman parte. La categoría de indio denota la condición de colonizado y hace referencia necesaria a la relación colonial (Bonfil 1972, p. 110)

Sobre el proceso de politización de la cuestión indígena (y de la ciencia, especialmente de la ciencia antropológica) escriben Lavaud y Lestage cuando afirman que "la atención prestada a los indígenas es tal que ha implicado - hace una década- cambios en los trabajos de las ciencias humanas sobre este tema, cada vez menos orientados hacia la cultura y cada vez más hacia las luchas políticas" (2006, p. 47). Consideramos que este proceso de politización e instrumentalización del debate en torno a la cuestión indígena le hace un flaco favor a la causa antropológica, aunque políticamente sea justo y útil. En este sentido, coincidimos plenamente con el filósofo español Ortega y Gasset, quien asienta su pensamiento sobre la teoría del perspectivismo y la razón vital, cuando escribe que:

Situada en su rango de actividad espiritual secundaria, la política o pensamiento de lo útil es una saludable fuerza de que no podemos prescindir. Si se me invita a escoger entre el comerciante y el bohemio, me quedo sin ninguno de los dos. Más cuando la política se entroniza en la conciencia y preside toda nuestra vida mental, se convierte en un morbo gravísimo. La razón es clara. Mientras tomemos lo útil como útil, nada hay que objetar. Pero si esta preocupación por lo útil llega a 
constituir el hábito central de nuestra personalidad, cuando se trate de buscar lo verdadero tenderemos a confundirlo con lo útil. Y esto, hacer de la utilidad la verdad, es la definición de la mentira. El imperio de la política es, pues, el imperio de la mentira (Ortega y Gasset 1971, pp. 17-18)

Somos plenamente conscientes de la complejidad del debate entre ciencia y política, más aun si hablamos de ciencias sociales, y está muy lejos de nuestra intención ahondar en esta cuestión aquí. Lo que sí debe ser subrayado es la necesidad del científico social de atender a la realidad política del contexto que le toca estudiar (aunque creemos que esto no implica confundir una actividad con la otra). Esta preocupación por lo político es necesariamente mayor cuando una de las conclusiones importantes que ofrecemos en este artículo es cómo, junto con la adquisición de un mayor nivel educativo y el desarrollo de cierta conciencia e identidad étnica, se da con cierta frecuencia un proceso de politización del indígena, mostrado a través de su implicación y activismo por la defensa de sus derechos.

Respecto a la preocupación por la contextualización política de la problemática, tan vinculada a la definición de lo que es ser indígena o quién es indígena, es la que especifica Friedlander (2007):

Conforme México hace su "transición hacia la democracia" el gobierno adopta el lenguaje de la diversidad. La gente habla más hoy acerca de dar a los indígenas sus derechos indígenas que acerca de ayudarlos a participar en un México culturalmente unificado. El pluralismo étnico ha reemplazado la imagen revolucionaria de un solo pueblo con una doble herencia; la nación mestiza ha cedido el paso al estado multicultural.

Respecto a la definición del indígena, esta autora coincide con Bonfil en asentarla sobre la condición de posición estructural de sometimiento, explicando cómo este es el elemento que ha permanecido inmutable al paso histórico de diferentes circunstancias y planteamientos socioeconómicos, demográficos, culturales e ideológicos:

A lo largo de los siglos, conforme las personas que pertenecían a las clases dominantes en México adoptaban nuevas costumbres y rechazaban las antiguas, exportaban sus viejas tradiciones a sitios remotos del país, rebajando frecuentemente estas prácticas recicladas a la condición inferior de "indio". Como resultado de ello, mientras los identificadores culturales estaban cambiando con frecuencia, la posición social de los indígenas permanecía esencialmente igual. Los indígenas seguían siendo "indios" por cuanto continuaban careciendo de lo que la elite mexicana continuaba adquiriendo (Friedlander 2007).

48 Es decir, pareciera que esta transición al "estado multicultural" es una operación de maquillaje en la que la esencialización del indígena como indigente y atrasado no experimenta ningún cambio significativo. No obstante, creemos que sí aparecen indicios de cierto empoderamiento de la población indígena a través de los dos elementos o agentes de socialización que, precisamente, son los que nos preocupan en nuestro artículo: los medios de comunicación y la educación superior. Un ejemplo de esto nos lo expone Zamorano (s.f.) cuando explica los debates generados acerca del Estado Plurinacional y la Asamblea Constituyente desde el proceso de apropiación de medios audiovisuales por parte de organizaciones indígenas originarias de Bolivia. La autora considera que "este proceso ha implicado un ejercicio de imaginación para buscar en el pasado, retomar y adaptar referencias míticas y políticas, así como reconocer la coexistencia de diferentes prácticas políticas en la historia de Bolivia" (Friedlander 2007). La autora pone el acento en la producción audiovisual indígena entendida como espacio 
generador de debate sobre la realidad en la que se imaginan y negocian escenarios posibles de presencia indígena en la política nacional.

En nuestro caso, a un nivel más microsociológico y sin entrar a analizar los contenidos transmitidos, veremos someramente algunos ejemplos de empoderamiento a través del uso de ciertos medios de comunicación, usados para reproducir una imagen mucho más cercana a lo que es percibido como propio. Concretamente, serán la radio y las redes sociales los espacios mediáticos en los que el joven indígena universitario encuentra dónde mostrarse (o donde se ve reflejado) según sus propios parámetros y sin la intervención de la imagen por una mano ajena y desconocida.

Por otra parte, desde un punto de vista global y yendo más allá del "paso al Estado multicultural" que describe Friedlander, desde la literatura especializada existe una marcada preocupación por los derroteros de este proceso hacia el multiculturalismo.

En las últimas dos décadas, el multiculturalismo, que en las clásicas sociedades de inmigración habían surgido como un movimiento de reivindicación de las identidades diferenciales de los grupos minoritarios o minoritizados, se ha ido convirtiendo y oficializando como un conjunto de filosofías de integración, como políticas públicas de reconocimiento de dichas minorías y de redefinición de las relaciones entre éstas y la sociedad mayoritaria (...) En el contexto latinoamericano el multiculturalismo comienza a sustituir las anteriores políticas diferenciales de corte indigenista, destinadas a los pueblos minoritarios (Dietz 2010, p. 309)

51 Este estado de la situación nos impone una exigencia ineludible: para abordar la actual problemática de la construcción de las identidades en general y, de las identidades étnicas en particular, debemos contextualizar esta problemática en la era globalizadora que vivimos. Bajo esta premisa, debemos reflexionar acerca del papel de las culturas en los tiempos del permanente contacto intercultural, "esta madeja de comunicaciones distantes e incertidumbres cotidianas, atracciones y desarraigos, que se nombra como globalización" (García Canclini 2005, p.13). Para ello, debemos entender que las sociedades multiculturales han sido superadas (aunque posiblemente no las políticas), pues la recreación constante fruto del contacto cotidiano entre grupos diversos nos obliga a plantearnos un nuevo modelo de convivencia. Tal y como explica García Canclini:

Las transformaciones recientes hacen tambalear las arquitecturas de la multiculturalidad. Los estados y las legislaciones nacionales, las políticas educativas y de comunicación que ordenaban la coexistencia de grupos en territorios acotados son insuficientes ante la expansión de mezclas interculturales (...) De un mundo multicultural -yuxtaposición de etnias o grupos en una ciudad o nación- pasamos a otro intercultural globalizado. Bajo concepciones multiculturales se admite la diversidad de culturas, subrayando su diferencia y proponiendo políticas relativistas de respeto, que a menudo refuerzan la segregación. En cambio, interculturalidad remite a la confrontación y el entrelazamiento, a lo que sucede cuando los grupos entran en relaciones e intercambios (García Canclini 2005, p.14)

Esto no significa que el encuentro intercultural constituya una novedad para la humanidad, pero sí lo es el crecimiento exponencial de la intensidad y el número de estos encuentros, de tal forma que prácticamente nadie escapa a su influjo. Acerca de la omnipresencia de este fenómeno, tanto en el tiempo como en el espacio, escribe Grimson:

Los procesos culturales, alejados de los tipos ideales que habitan las identidades, son procesos de intersección. Todos vivimos en intersecciones culturales y, como individuos, residimos en intersecciones peculiarísimas que, a su vez, irán transformándose a lo largo de la vida. La interculturalidad no es un fenómeno novedoso (...) El término "interculturalidad" es una forma relativamente nueva de nombrar un proceso histórico (Grimson 2011, p.190) 
Producto de estas nuevas dinámicas globales, desde la comunidad científica han proliferado las propuestas terminológicas para tratar de delimitar los resultados de los procesos de la interculturalidad, tratando de distinguir la imitación de la apropiación, la acomodación de la negociación, la mezcla, el sincretismo, el hibridismo o la creolizacion (Burke 2010). Creemos que en los tiempos de la globalización es una exigencia de la época el replanteamiento de la identidad colectiva, reconstruirla aportando pero también adquiriendo elementos de todos aquellos con los que convivimos y, finalmente, construyendo un nuevo "nosotros".

El debate entre multiculturalismo, multiculturalidad, interculturalidad y las políticas que han materializado estos planteamientos es complejo y excede el límite del objetivo planteado en este trabajo, motivo por el que no lo desarrollamos en toda la profundidad que merece. En cambio, a continuación, ofrecemos un rápido repaso por algunos de los estudios empíricos que se acercan a nuestro objetivo de investigación.

\section{Antecedentes empíricos}

En lo que se refiere a los estudios que se han desarrollado para comprender el modo en que los indígenas americanos se insertan en la era de la globalización a través de la influencia de los medios de comunicación de masas, estos se centran en dos aspectos fundamentales: la forma en la que el indígena es estereotipado y en que esta imagen estereotipada es interiorizada por el mestizo (Nahmad 2007; CDI 2006; Muñiz 2013; Moreno 2010); la utilización de los modernos medios de comunicación por parte de los indígenas como forma de representación de la propia identidad o como herramienta de lucha política (Espinosa 1998; Esteinou, Loera y Peniche 2002; Cisneros 2006; Castells 2003; Flores 2005; Zamorano s.f.). Nótese que estos trabajos se agrupan temáticamente en los dos polos tensionales que, como hemos explicado en el apartado anterior, genera la globalización: la tendencia centrípeta al reforzamiento de identidades étnicas y la centrífuga hacia la disolución. Es decir, hay estudios que hacen hincapié en el proceso de empoderamiento y lucha política y otros que se centran en los procesos de sometimiento y estigmatización.

Con un enfoque menos politizado que los anteriores, el reciente estudio de García Domingo sobre la comunidad indígena venezolana Jivi de Ekunay ofrece una exhaustiva etnografía describiendo su organización social, sus dinámicas de comunicación interpersonal, su lingüística, sus rituales entendidos como procesos de comunicación, su comunicación mediante mitos y leyendas y su comunicación política. En suma, lo que pretende la autora es "recopilar y documentar el cuerpo de relatos y ceremonias a través de los cuales se transmiten los mensajes de la cultura tradicional Jivi de Ekunay. Se tratan procesos de comunicación interna ancestral en riesgo de desaparecer, y nuevos procesos de comunicación política claves en la relación de este pueblo con su contexto político" (García 2015, p. 23). No obstante, en este minucioso trabajo la autora no presta atención a un elemento clave para nosotros: los medios masivos de comunicación.

57 El efecto que produce la proyección estereotipada del indígena sobre la identidad del mismo es resaltado por Nahmad en la siguiente cita, dando de nuevo el paso hacia el activismo político, pues esta autora reclama la urgencia de revertir o resistir los embates de la cultura hegemónica permitiendo la apropiación de los medios y la posibilidad de que el indígena recree él mismo su propia imagen mediática. 
Los pueblos originarios pugnan cotidianamente contra los estereotipos y representaciones coloniales que los han subyugado por siglos, por una parte, reapropiándose de una identidad que les fue formulada por el grupo dominante $\mathrm{y}$, por otra, adueñándose de los medios para definir por sí mismos y según sus propios criterios su identidad. Una manera de tomar las riendas para construir y reformular su propia representación es mediante el manejo de los medios de comunicación, como es el caso de la radio, el cine y fundamentalmente el video, en los que intentan otras formas de articulación discursiva que subviertan las visiones vacías de las hegemonías culturales, construyendo nuevos órdenes discursivos (Nahmad 2007, p. 114)

Íntimamente relacionado con la cuestión de la identidad étnica en Latinoamérica y el papel de los medios de comunicación aparece la difusión, a través de estos, de las lenguas indígenas. Este es una de las dimensiones de la problemática que vamos a considerar en nuestro trabajo, y también es una dimensión ya abordada por otros científicos sociales. Tal es el caso de Uribe-Jongbloed, el cual propone, como complemento a los estudios europeos de medios en idiomas minoritarios, "que la investigación sobre medios en idiomas minoritarios en América Latina opte por una aproximación contextual que estudie los procesos de negociación de identidad y la capacidad participativa, definidas bajo los conceptos de hibridación y convergencia" (Uribe-Jongbloed 2011, p. 3). Es decir, nuevamente nos encontramos ante una propuesta que pretende ir más allá del mero análisis científico para adentrarse en el terreno del cambio social, pues:

\footnotetext{
La Comunicación para el Cambio Social, un campo de estudio y trabajo práctico que involucra participantes de diversas disciplinas, ha comprendido el valor que tiene la comunicación en procesos de desarrollo local y ha promulgado la importancia de la participación de las comunidades en sus proyectos de desarrollo, incluyendo el uso de su propio idioma dentro de estos (Uribe-Jongbloed 2011, p. 4).
}

Otro trabajo que aúna la preocupación por las variables etnicidad, emigración y medios de comunicación es el realizado recientemente por Antonieta Mercado (2015), quien ofrece una reflexión acerca de las prácticas de indígenas oaxaqueños (mixtecos y zapotecos) emigrados a Estados Unidos en lo que se refiere a la construcción de productos mediáticos. No obstante, con el enfoque de Mercado, orientado hacia la comprensión de la construcción de una ciudadanía transnacional, nos desviamos de nuestro propio planteamiento, por lo que cerramos en este punto la revisión de nuestros antecedentes empíricos.

Igualmente, para no desviarnos de nuestro propio planteamiento, tampoco hemos abordado los numerosos estudios que abordan la problemática de la identidad étnica y el acceso de los indígenas a los niveles superiores de educación (Ampuero 2013; Olvera, Doncel y Muñiz 2014), centrándonos únicamente en los que consideran específicamente el papel de los medios de comunicación de masas en la construcción de la identidad étnica.

\section{Presencia y valoración de las lenguas indígenas en los medios de comunicación de masas consumidos por los estudiantes indígenas}

61 A continuación, analizamos las respuestas obtenidas respecto a la presencia de la lengua del entrevistado en los medios que utiliza en la sociedad de acogida, discriminando a partir de la variable que consideramos más significativa por suponer dos momentos muy distintos del proceso de construcción de la propia identidad: el nivel de estudios 
(preparatoria o universidad). Así, encontramos una clara homogeneización en las respuestas entre los estudiantes de preparatoria, pues la gran mayoría de los mismos afirmó tajantemente que no habían escuchado su idioma en ninguno de los medios que utilizan en Monterrey. Solo una de ellos, una estudiante hablante de náhuatl, afirmó haber escuchado ocasionalmente su idioma en la televisión, específicamente en algunos comerciales de gobierno.

En la siguiente cita mostramos cómo esta respuesta negativa puede ir acompañada de una fuerte expresividad en el caso de una de nuestras informantes adolescentes, la cual a lo largo de la entrevista dejó entrever en numerosos momentos una contundente actitud de rechazo a la propia identidad étnica. De la forma en la que es respondida la pregunta podemos interpretar que a esta entrevistada le parece absurda e inconcebible la idea de que su idioma "merezca" aparecer en los medios de comunicación, lo cual, sumado a la forma despectiva de referirse a los huicholes ("o esos"), es coherente con su discurso despectivo o desvalorizador de su propia procedencia étnica.

Entrevistador: Bueno, alguna vez ¿has escuchado programación en tu dialecto ${ }^{11}$ ?

Informante 1: ¿Qué?, claro que no.

Entrevistador: Bueno, ¿qué has escuchado o leído en los medios de comunicación

sobre tu cultura?

A: Nada, nunca hablan de la Huasteca, no que yo haya oído.

Entrevistador: $¿ y$ sobre otras culturas indígenas?

A: No sé, a veces veo que dicen de los huicholes, o esos, pero no sé porque no escucho el radio.

En el caso de los estudiantes universitarios, al igual que sucedió para el análisis de los usos dados a los medios de comunicación, la tendencia cambia. Aquí se da cierto equilibrio entre los que utilizan medios que emiten en sus respectivos idiomas y los que no los conocen, de tal modo que exactamente la mitad de los entrevistados universitarios afirmaron escuchar o leer, con mayor o menor frecuencia, sus idiomas maternos en los medios que utilizan. Esto nos aproxima a la idea, que deberá ser corroborada en posteriores trabajos, de que en el nivel educativo superior el sujeto adquiere conciencia sobre su propia identidad étnica, superando la fase de autoocultamiento que detectamos para el nivel medio superior en el estudio mencionado anteriormente (Olvera, Doncel y Muñiz, 2014). Así, nos encontramos con que muchos universitarios indígenas no solo consumen pasivamente medios en su idioma, sino que además algunos de ellos son creadores de productos mediáticos para la difusión de su lengua y su cultura. Tal es el caso de un informante de etnia náhuatl, cuando nos explica que:

Pues, sí... tenemos la radio, que es 'La Voz de la Huasteca', como te comentaba... que es programa de radio que está enfocado a comunidades... Lo hacemos de aquí en Monterrey y lo transmitimos en vivo allá... La estación se llama 'La Voz de la Huasteca', 170 AM... Lo puedes buscar ahí en internet, y habla más que nada... es radio ahí. En realidad hablan... como hay varios idiomas, hay tres idiomas... el náhuatl, el tének, y pame... (Informante 10)

64 Al igual que mencionamos en estudios anteriores (Doncel, en prensa), la radio vuelve a aparecer como medio idóneo para el reforzamiento de vínculos identitarios, en este caso una dimensión identitaria que va más allá de la comunitaria o la étnica, pues abarca la que podríamos considerar identidad regional de carácter multiétnico (la que se circunscribe a la región de la Huasteca Potosina ${ }^{12}$ ). Pero no es solo este medio el que sirve de soporte a la elaboración de mensajes en lenguas indígenas, como podemos apreciar en la siguiente cita, enunciada por un estudiante náhuatl de posgrado y licenciado en Derecho. Según nuestro informante, a pesar de que la presencia de contenidos en náhuatl 
es muy limitada, quedando opacada completamente por los contenidos en español, aparecen las redes sociales como espacio virtual en el que algunos inmigrantes indígenas distribuyen contenidos de sus culturas y en sus lenguas (de hecho son radio y redes sociales los dos medios de comunicación mencionados por todos los entrevistados que afirman consumir productos mediáticos en su idioma materno). Por otra parte, aquí aparece en nuestro informante una identificación que trasciende la dimensión étnica y la regional aspirando a una identidad indígena (¿quizás transnacional?). Esto se deduce cuando el informante habla de "algunos compañeros que traen contenidos (...) en lenguas indígenas", pudiendo encontrar un posible factor explicativo a esta ampliación del círculo identitario en el hecho de que se trata de una persona muy activa políticamente en la defensa de los derechos indígenas en el estado de Nuevo León.

Entrevistador: Desde la Internet, ¿sueles encontrar información en náhuatl o es más en español?

Informante 22: Pues más en español, todo en español a menos de unas redes que hay más... pues de Facebook. Si hay algunas páginas que son elaboradas por algunos compañeros que traen contenido, pues... en lenguas indígenas. Pero eso es por las redes que tenemos, pero más allá de eso... no, no hay ningún medio que sea así.... Uno que otro spot que sea de tele o radio o en electrónico que es... en lenguas indígenas, pero son muy pocos. Son muy raros.

En la siguiente cita vemos cómo los esfuerzos para la creación de productos mediáticos propios son recibidos por el consumidor, así como podemos apreciar cómo esta preocupación por lo propio suele ir acompañada de cierto grado de conocimiento respecto al fenómeno del que el informante forma parte. Además, aquí se presenta una concepción de la propia identidad étnica vinculada directamente a la identidad nacional, aunque con cierta reserva, si es que podemos interpretar como titubeo la interjección "ese tipo de cosas... eem... mexicanas". Se trata, en este caso, de un estudiante de negocios de etnia náhuatl:

Mira, tengo éste... gratamente se podría decir, tengo muchos amigos que les encanta lo que es difundir la tradición de San Luis Potosí y todo ese tipo de cosas... eem... mexicanas, entonces ellos se dedican más a difundirlo.... a tratar de reavivarlo, a que no desaparezca. Que ¡vaya! aquí... sobre todo aquí en Nuevo León, se dice que Nuevo León es el estado actualmente con el índice más alto de migrantes y de muchas lenguas (...) O sea, ¿por qué? Porque aquí en Nuevo León, aquí en Monterrey es un estado en donde la economía se podría decir [que] es buena, hay mucho trabajo, mucha demanda de trabajo. Entonces ¿qué es lo que hacen los estados de índice baja... económicamente? Llegan y empiezan a trabajar aquí, entonces, es un... es una mezcla de muchos.... muchas, muchas lenguas y entonces lo que se quiere hacer estos chavos, que conozco, lo que sé... lo que quieren es difundirlo (...) Y han hecho muchos eventos aquí en Monterrey, para que se vea quiénes estamos aquí y todo eso y no haiga mucha discriminación. Aquí en Monterrey hay mucha discriminación (...) Pero o sea así es, se me hace muy raro, hay mucha discriminación y en sí en cantidad de personas migrantes y eso es lo que hacen ellos y éste... gracias a Dios yo los conozco, porque a mí también me gusta eso de las tradiciones. Tengo otros objetivos, pero me parece muy interesante conocer en qué sí y poder en lo que pueda colaborar, pues está muy bien (Informante 17)

El informante anterior concluye subordinando su actividad colaborativa en la difusión de su cultura a otro tipo de intereses, de modo que su "activismo" en este aspecto es un complemento a su actividad profesional. Durante nuestro trabajo de campo hemos encontrado varias situaciones en cierto sentido opuestas a la anterior, pues es la actividad profesional la que empuja al sujeto a consumir productos mediáticos en su lengua materna. Este es el caso de dos maestras que aseguran consumir este tipo de producto por 
necesidad profesional, una de las cuales, maestra de educación indígena en primaria, nos explica que lee en su idioma “

pues sí, uno tiene [que hacerlo], bueno, yo en mi caso sí leo mucho, porque pues de eso se trata mi... de lo que estoy trabajando con los niños de Educación Indígena y sí tengo... (...) es en lengua indígena las clases (...) Entonces sí tengo que leer libros o a veces en la planeación, pues tenemos que meter algunas palabras también en lengua indígena... vocabulario más que nada es lo que manejamos (informante 13)

De entre los universitarios entrevistados que negaron consumir o conocer medios en Nuevo León que trasmitan su idioma destacamos dos respuestas que representan dos posturas opuestas: la postura del indígena desvinculado de su comunidad y de su cultura y el indígena concienciado y crítico con la poca atención que se le presta a las lenguas y culturas indígenas. La primera de ellas, una mujer huasteca que trabaja de niñera, al ser preguntada acerca de su consumo mediático en idioma huasteco afirma que "ni hacen cosas en huasteco... pero si hacen, pues no las he visto, porque nunca voy a San Luis. En Navidad voy, pero no he visto nada que esté en huasteco" (informante 15). La postura mucho más crítica y concienciada nos la ofrece un hombre hablante de náhuatl, quien realiza un breve análisis semiótico de su lengua para justificar la ausencia del mismo en los medios masivos de comunicación:

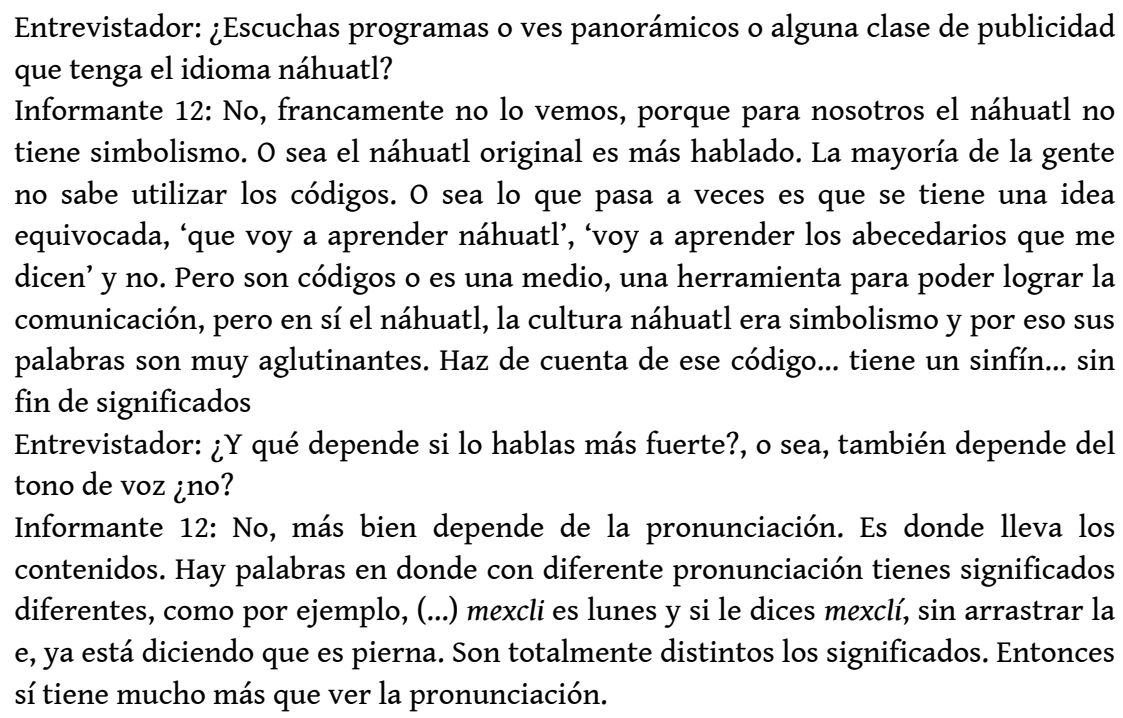

\section{Significación que los estudiantes indígenas dan a sus culturas representadas en los medios de comunicación de masas}

Cuando suprimimos la variable lingüística y preguntamos a nuestros informantes acerca de la emisión de productos mediáticos con contenidos propios de sus culturas en idioma español, muchos más respondieron afirmativamente. Entre los estudiantes de preparatoria siguieron siendo minoría los que afirmaron haber visto en los medios mensajes de este tipo, pero ya fueron más de la tercera parte. Por su parte, entre los universitarios la inmensa mayoría afirmó haber visto programas en los que se representa a su grupo étnico o a otros pueblos originarios (de hecho, ni uno solo de los estudiantes universitarios negó rotundamente haber visto ningún producto mediático de este tipo). 
69 Es decir, de nuevo encontramos que el desarrollo académico viene acompañado de cierto desarrollo (¿o recuperación?) de la identidad étnica. Ofrecemos a continuación dos citas que, en cierto modo, ilustran este contraste entre la conciencia y el conocimiento de lo propio que muestran estudiantes de preparatoria y de universidad. La primera cita es enunciada por una mujer ya egresada de preparatoria y con una edad superior a la media de los estudiantes para este nivel académico (tiene 20 años), motivo por el que ya podemos percibir cierto orgullo por la propia adscripción étnica. Es decir, parece que nos encontramos en un primer momento de la superación de la autonegación adolescente de la propia identidad, aunque la cita expresa a la perfección una clara indefinición cultural, o más bien una incapacidad para expresar y describir en qué consiste la propia cultura. No obstante esta confusión de orden cognitivo esconde un sentimiento latente de orgullo de lo propio.

Entrevistador: ¿qué has escuchado o leído en los medios de comunicación sobre tu

cultura?

Informante 5: Sobre mi cultura...

Entrevistador: ¿Alguna vez has visto noticias o algo?

Informante 5: Pues de que es muy... ¿cómo diré?, o sea, es rica en... (...) que es muy... ¿cómo le diré?, que pues tiene muchas... ¿cómo le diré?, o sea, que es muy rica en lo que hace, en la lengua. Pues porque es como nosotros, nos dicen que... pues de que somos... de que hablamos dos lenguas, que somos pues... que dicen '¡wow!, hablan dos lenguas' (...) Pues el español (...) y el tének, que dicen de que 'no, pues deben sentirse orgullosos'.

El contrapunto a esta muestra de confusión cognitiva lo pone un estudiante náhuatl que, además de universitario, es muy activo en la defensa de los derechos indígenas a través de varias asociaciones civiles. De su discurso emana una profunda concienciación de lo que es "ser indígena", así como un amplio conocimiento de los valores que él considera propios del indígena, una elaboración de esta cosmovisión “indígena” y, en definitiva, una identidad indígena (multiétnica) muy fortalecida. Esta identidad se muestra como algo interiorizado de manera sólida cada vez que el informante se refiere al "nosotros" o a "los hermanos huicholes".

Entrevistador: ¿Has escuchado o leído en algunos de estos medios de comunicación algo sobre tu cultura?... o sea, no el idioma, sino tu cultura.

Informante 10: Este... sí. He leído varios este... he visto documentales, ¿no?, ya sea de mi cultura y aparte culturas también hermanas (...) La de los hermanos huicholes, los guardianes del peyote... Es que nosotros vemos, más que nada, [que] la naturaleza o la tierra es como la madre... ¿no? la madre tierra. Y en sí nosotros como indígenas respetamos los elementos, ¿no?, que son muy importantes... [elementos] como el fuego, el aire, el viento y el agua, ¿no? Que no son cosas como jugarlos o son cosas que nomás usarlo, sino... siempre hay veces, ocasiones, digamos [que] son días, pero bien determinados, que se tiene que dar una ceremonia de agradecimiento, ¿no? (...) Sin ellos no seríamos vitales, ¿no?, es el complemento, ¿no? Y pues ya eso de que también embona en conjunto con la madre tierra y por eso sí [hay que] tratar de cuidarla. No es nomás vivir aquí en la tierra y ya.

71 En cuanto a la valoración del contenido temático de los programas visionados por nuestros informantes podemos agruparlos en dos: los que ofrecen una versión positiva de la transmisión de las culturas percibidas como propias y los que inciden en el papel estigmatizador que tienen los medios respecto a estas culturas. Cuantitativamente fueron muchos más los informantes que dijeron disfrutar cuando consumen contenidos de carácter indígena (14 entrevistados frente a 6 que mostraron indiferencia, 3 una posición ambigua y 5 una posición crítica y negativa), coincidiendo todos ellos en la importancia 
de dar a conocer sus culturas, de que estas obtengan un reconocimiento social a través de su proyección en los medios y en el orgullo que sienten por su origen étnico.

Este orgullo, antesala de una identidad social consolidada, en ocasiones tomó la forma de identidad indígena por oposición a la identidad nacional, como es el caso del informante 20 cuando afirma que:

la verdad muchos [de los mestizos] no nos conocen o nos creen como diferentes, pero pues somos como ven a los que nacen en Estados Unidos... pero pues nacimos en su mismo país, pero hablando otro idioma y pues no tenemos nada... o bueno, no tiene nada de malo (informante 20).

En otras ocasiones este orgullo adquiere envoltorio de identidad nacional, aunque en la cita donde se menciona esto podemos interpretar cierta reserva o ironía cuestionadora de dicha identificación: "Pues sí se siente orgulloso [cuando los medios tocan temas de su cultura] de lo que es ser mexicano, como le dicen [risas]" (informante 19).

Más allá del orgullo que experimentan al ver en los medios una representación de sus culturas, llama la atención cómo el hecho de ser incluido en la programación de los medios de una cultura aceptada como dominante es percibido como un premio, como un reconocimiento hacia ellos mismos. Así lo expresa un informante náhuatl y con licenciatura ya terminada: "No, no, no... o sea, no me incomoda [que los medios toquen temas indígenas], porque creo que es algo significativo para mí y me da esta... como una cierta relevancia el saber que ya... este... nos están ascendiendo" (Informante 23). De esta cita se deduce en el informante una clara concepción jerárquica de las relaciones entre grupos sociales caracterizada por la verticalidad, asumiendo la posición inferior de su propio grupo de adscripción así como el ideal aspiracional del ascenso a través de su aparición en los medios de comunicación dominantes.

En cuanto al contenido de los mensajes a los que se refieren los informantes que muestran agrado por la emisión de los mismos, estos se centran en diversas manifestaciones culturales de sus pueblos originarios. Tal es el caso de un hombre náhuatl de 49 años que truncó sus estudios universitarios en su juventud. En su respuesta nos ofrece una visión muy optimista, mostrando una posición integradora (en el sentido que Berry -1980- da al término) y centrándose en el papel de los medios como transmisores de la riqueza y heterogeneidad de su cultura.

Entrevistador: ¿ $i$ Ha escuchado algo acerca de su ciudad de origen y de su cultura aquí en Monterrey?

Informante 28: Sí, si lo he escuchado, pues hablan de mi comunidad que... pues están revitalizando el idioma aquí en el área metropolitana. Me siento muy contento de escuchar que mi comunidad o la Huasteca están revitalizando el idioma. Está revalorizando todo lo que nos dejaron nuestros ancestros. Entonces yo menciono mucho de que Monterrey es Huasteca y la Huasteca es Monterrey.

Entrevistador: ¿Qué ha escuchado de los medios de comunicación acerca de su cultura?

Informante 28: Pues la tradición de lo que cada comunidad tiene, las palabras variantes que existen en cada comunidad, las tradiciones, las festividades, sus mercados... no sé, todo lo que implique de su comunidad.

En la misma línea de la anterior cita, aunque expresada de manera más sencilla y refiriéndose a un medio más acorde a la edad del informante (18 años), aparece la respuesta que se refiere a la reproducción de un aspecto del folclor de su sociedad a través de internet:

En la computadora, en internet (...) veo video. Es que los domingos tienen un baile que se llama los huapangos y entonces los suben y yo los veo $u$ otras chicas 
[compañeras de la residencia religiosa donde se aloja] me los enseñan (informante 6). de casos exitosos de niños indígenas que han ganado concursos educativos, lo que invariablemente es narrado con orgullo, resaltando su valor ejemplarizante para el resto de la comunidad. En este campo de intersubjetividad coincidieron una estudiante de enfermería de etnia mazateca (informante 27) y dos maestras, una de etnia huasteca (informante 13) y otra de etnia náhuatl (informante 20).

La otra cara de la moneda se compone del grupo de respuestas que muestran disgusto o enojo por la imagen que los medios proyectan de sus culturas o de sus identidades, poniendo el acento unas veces en el carácter vejatorio, otros en el discriminador y otros en el victimizador de estos contenidos mediáticos. En este sentido, es muy clara nuestra informante 16, estudiante universitaria de etnia mixe, cuando narra el caso que leyó acerca de una empleada doméstica de origen indígena y sobreexplotada por su patrona ${ }^{13}$. En el siguiente fragmento surge entre el entrevistador y el informante un interesante debate acerca de la pertinencia o de la valoración de que los medios emitan casos extremos de discriminación hacia la población indígena, pertinencia dada por la generación de conciencia en la población (expresada soterradamente por el entrevistador) frente a la crítica de una emisión entendida como inútil en términos prácticos; crítica de una desigualdad extrema en la distribución social del trabajo y crítica de una igualmente extrema insolidaridad social (expresada por la entrevistada).

Informante 16: Apareció una publicación de empleada doméstica en El Norte. Decía... espera, deja recordar... no me acuerdo qué publicaron, pero pusieron que una chica, empleada doméstica, migrante de San Luis, de los trabajos...

Entrevistador: Yo había visto una de discriminación y bajo sueldo que daban.

Informante 16: Eso. El trabajo es más de ocho horas, pero no les dan descanso para comer, para descansar también ni para... o sea, para hacer otras actividades no les dan otras oportunidades para hacer en su día. Están atadas por la patrona. No sé si sea miedo o sea por el trabajo que les ponen para que realicen durante el día y no lo terminen hasta la noche. Es muy pesado, dependiendo de las actividades. Luego tú te preguntas por qué ellas trabajan si la patrona puede hacerlo también.

Entrevistador: ¿Entonces no estás de acuerdo?

Informante 16: No, no lo estoy. Es como si fuera patrona y tengo alguien que me ayude. No le pondré a hacer todo (...)

Entrevistador: Pero... entonces, ¿te gusta que publiquen, en este caso, esta información de que la empleada fue discriminada?, [que] tiene mucho trabajo o [que] no se le paga lo suficiente para todo lo que hace. ¿Te agrada que las den [estas noticias]?

Informante 16: No me agrada, porque lo publican pero no hacen nada. Es muy fácil hacer eso... digo 'mira, aquí está', pero nada cambia. Al menos [podrían] hacer algo y ver el resultado de la ayuda que le dan, pero solo publican: 'mira, tal persona sufrió discriminación', pero nadie le da una ayuda, orientación, ni nada.

Entrevistador: Entonces el que lo publiquen, ¿no cambia nada?, ¿que lo digan a la sociedad? Por ejemplo, que sea discriminada y tú compras el periódico y ves la nota... ¿no hay un cambio?

Informante 16: Cuando compras el periódico y lo ves... pues solo lo lees y ya. La gente solo se informa con eso. ¿Quién hace algo? Nadie lo hace. Pero la persona que 
lo está publicando... al menos tienes que hacer algo. Ahí está la persona y dónde sucedió, pero como no tenemos vinculación con esa persona, puede ser que no nos permita ayudarle, por las situaciones diferentes.

Nuestra siguiente informante, estudiante universitaria de etnia náhuatl, pone el acento en el papel estigmatizador y reproductor de estereotipos de ciertos programas de televisión, aunque en último término también afirma haber visto algunos programas que muestran tradiciones y costumbres indígenas (lo cual sí valora positivamente). No obstante, en el discurso se impone esa percepción del mensaje vejatorio a través de la burla hacia el otro, al foráneo e indígena.

Entrevistador: ¿Has escuchado algo en los medios de comunicación de tu cultura? Informante 18: Hmmm... pues lo que he escuchado es discriminación, o sea como que no se les da el mismo apoyo a la gente que viene de allá.

Entrevistador: Ok, ¿en qué medio lo has visto?

Informante 18: En este... en la televisión, cuando pasan programas... por ejemplo, las de las nueve, como que ridiculizan a las personas que van a cantar y todo (...) Entrevistador: Ok, ¿cuál es esa que me dices que van a cantar?, la de aficionados... Informante 18: $\mathrm{Si}$, la de aficionados que van así... este... que son personas que van de San Luis o de Veracruz y van a cantar y, por ejemplo, como no pronuncian bien el español y lo dicen de otra manera ellos se empiezan a reír y todo...

Entrevistador: (...) Este... cuando... cuando ves ese tipo de cosas, ¿te incomoda o qué sentimiento te da?

Informante 18: Pues sí me incomoda, porque pues todos somos iguales.

Entrevistador: Ok, ¿y te ha tocado ver en los medios de comunicación que toquen temas de culturas indígenas?

Informante 18: Hmmm... sí pero es muy poco, no es tanto.

Entrevistador: ¿Y como cuales son los temas que ves que toman?

Informante 18: Este... sobre como que fiestas que se celebran en otras culturas o gastronomías

Entrevistador: ¿Y te incomoda ver esos tipos de temas?

Informante 18: No, eso no... O sea, porque como que se da más este... como que atraer más a la gente para que vaya a visitar esos lugares.

81 Por su parte, la informante 15, estudiante de la licenciatura educación y de etnia huasteca, expone una percepción según la cual el indígena aparece representado como alguien pobre y necesitado de ayuda.

Entrevistador: ¿Qué has escuchado o leído en los medios sobre tu cultura?

Informante 15: Es que casi no veo que digan nada nunca de los huastecos, o a veces

sí... cuando pasaban el Teletón, creo. No sé.

Entrevistador: ¿Qué te acuerdas que salía en el Teletón?

Informante 15: Ah, no sé, digo... que a lo mejor ahí lo veía que decían que dones

para nosotros, pero no sé.

Esta percepción, en forma de crítica, también ha sido expresada por otros informantes y consideramos que refleja una de las más graves problemáticas referidas a la representación del indígena que los medios de comunicación mexicanos difunden: la victimización del indígena. La influencia de esta proyección de los indígenas sobre la representación que del mismo elaboran los jóvenes nuevoleoneses (los cuales no tienen prácticamente ningún contacto interpersonal con aquellos), fueron mostrados en un trabajo anterior (Doncel 2013). En este estudio mostramos, entre otros hallazgos, que los jóvenes que formaron parte de nuestro universo estereotipan a este colectivo humano asociando de manera prácticamente automática el concepto que tienen de indígena con el de indigente. 
83 Esta imagen proyectada del indígena, ya no solo como indigente, sino como ignorante y analfabeto (atributos también interiorizados por los jóvenes nuevoleoneses considerados en el citado estudio), es expresada por una de nuestros informantes, estudiante de preparatoria de etnia tének. La consecuencia, en este caso, se traduce un claro rechazo de la propia identidad étnica, como apreciamos en la siguiente cita. También hay que considerar que la entrevistada se encuentra en una edad adolescente (17 años), etapa vital en la que la construcción de la identidad social se construye en gran medida sobre el sentimiento de anormalidad, sobre el sentirse diferente y sobre el rechazo de lo propio ${ }^{14}$ (Díaz 2006).

Entrevistador: ¿Consideras que los medios son racistas?

Informante 1: Sí, porque ponen a los indígenas como si fuéramos tontitos y pobres.

Y no somos.

Entrevistador: Entonces, ¿Te sientes identificada cuando en los medios mencionan a los indígenas?

Informante 1: Pues no, porque no soy tonta, ni pobre. No soy rica, pero no soy pobre (...)

Entrevistador: ¿Te incomoda o te gusta cuando los medios tocan temas de indígenas?

Informante 1: Me incomoda porque soy normal, no soy otra cosa, y me preguntan como si yo me analizara. Pues no me analizo, porque así soy yo. Pero no veo que los toquen. No sé.

84 En la siguiente cita nuestra informante, joven universitaria de etnia náhuatl, además de señalar nuevamente una imagen del indígena representado invariablemente como "tonto", critica cierta folclorización del indígena en la representación que del mismo ofrecen los medios al mostrarlo regularmente con sus vestimentas tradicionales. Este comentario nos muestra otro eje del debate referente a la integración del indígena en el mundo moderno globalizado frente a su conservación y cosificación como garante y custodio de una tradición entendida en el plano simbólico como esencia de mexicanidad, pero despreciada en el plano material cotidianamente por ser considerada sinónimo de atraso social y cultural (Doncel 2013).

Entrevistador: $\mathrm{Y}$ ite incomoda, te gusta cuando los medios tocan temas de indígenas?, ¿por qué?

Informante 21: Sí (me incomoda), porque muchas veces este... pasan a la gente con vestimenta que ya ni se usa. 0 , por ejemplo, este... como que... como que así... no sé cómo explicarte, así como que... como que [los representan como] tontos.

85 Una visión igualmente crítica pero mucho más elaborada que la anterior es la que nos ofrece nuestro informante 22, estudiante de posgrado de etnia náhuatl. En su discurso explica los mecanismos por los que el tratamiento estigmatizador de los medios hacia la población indígena se convierte en destacado factor de generación de estereotipos y prejuicios entre la audiencia hacia este colectivo humano. En este caso se refiere a un acontecimiento que es convertido en indicador de inmoralidad, yendo más allá de los anteriores mensajes vejatorios, victimizadores o folclorizadores ${ }^{15}$.

Pues la verdad sí me molesta cuando [los medios hablan de indígenas], más cuando se estigmatiza... Algunos medios son muy propensos a eso, a estigmatizar cuestiones. Es más fácil, por ejemplo, algo así como que puede llamar mucho la atención: 'una familia indígena en'... no sé, en 'Oaxaca, vende a su niña por... este... 20,000 pesos. Doce años' y esas cosas. Entonces como que es una información que sí atrae gente, llama mucho la atención, y muchas veces sí, con una nota de esas, eh... te atrasa mucho tiempo para poder sensibilizar sobre algunos términos y una vez que tal persona vendieron, 'los indígenas venden a las niñas', se generaliza y es muy 
incómodo generalizar (...) Entonces como esas cosas [el hecho de que la población indígena de México es la que cuida la mayor parte de las áreas naturales protegidas del País], los medios no los manejan, pero una nota así de estigmatizar sí, y eso a mí la verdad eso me enoja mucho (Informante 22)

Finalmente, en un terreno de mayor ambigüedad valorativa se mostraron algunos de los entrevistados, haciendo depender su posición personal del contenido del mensaje, de la forma de tratarlo e incluso del lugar de la emisión (en la sociedad de acogida o en la de origen). Tal es el caso de nuestra informante 14, la cual en un momento de la entrevista cuestiona el tratamiento victimizador a través de una noticia referida a discriminación escolar, en un segundo momento alaba un programa en el que se expone una problemática social de su lugar de origen $\mathrm{y}$, en un tercer momento, se muestra especialmente emocionada e identificada cuando se refiere a los programas hechos y emitidos por miembros de su mismo grupo étnico desde su lugar de origen. Aquí cabe preguntarse si la emoción mostrada en el último momento (y el interés en el segundo) no viene dada por una nostalgia de lo local, más que representar una querencia por una cultura entendida en términos más abstractos, lo que correlacionaría con una identidad en la entrevistada más marcada por su carácter comunitario que por el étnico o el indígena.

Primer momento:

Entrevistador: ¿En general te incomoda cuando los medios tocan temas de indígenas?

Informante 14: Cuando estoy aquí [en Monterrey], sí. Cuando estoy allá en mi pueblo, no (...)

Entrevistador: ¿Me puedes poner un ejemplo?

Informante 14: Bueno, (...) la noticia de Multimedios que recientemente salió... (...)

Era de una señora que estaba haciendo... jah! que acudió a poner una denuncia porque su hijo había sido víctima de agresiones por... por hablar la lengua que... mmmh, materna, de su origen. $\mathrm{Y}$ entonces estaba siendo objeto de agresiones y de burlas y de... de los maestros y de los compañeritos (...) Entonces, total que, ah, no manejaron bien el tema y siento que al final estuvieron dando otro mensaje totalmente diferente a lo que realmente se estaba buscando (...) Siguen reforzando esa idea al decir que... que... eh... [El conductor de las noticia] remarcaba que somos más vulnerables. [El conductor decía que] 'a pesar de la condición (indígena) de ese niño llevaba los mejores promedios'. O sea, el decir 'a pesar de la condición', ya estaba igual reforzando esa idea de cómo nos está poniendo a todos...

\section{Segundo momento:}

Este fin de semana... hay un programa que a mí me gusta mucho y es un programa que es como tipo novela, pero presentan casos reales y este fin de semana vi... vi un caso que me llamó mucho la atención por el nombre que tenía. Me llamó mucho la atención porque tenía un título, pero después de ese título venía el nombre de Tanlajás en San Luis Potosí. Bueno, nomás por eso vi el capítulo que duró tres horas y era sobre la violencia que viven las mujeres indígenas en las comunidades... y me gustó mucho porque reflejaba la realidad del machismo que hay en las comunidades (informante 14)

Tercer momento:

Entrevistador: Me decías que el tratamiento que se da en los medios de tu comunidad... (...) ¿Ahí si te gusta?

Informante 14: [Emoción] ¡Sí, me gusta! Además uno sabe que la persona que está hablando es de la misma comunidad. Bueno, no perteneciente de ahí mismo, sino de otra comunidad, pero finalmente está en el mismo contexto (...) misma cultura, [mismas] vivencias. Y son muy... no sé, extraño esos programas, porque son buenos. 
90

Esta misma ambiguedad y este mismo sentimiento nos la muestra nuestra informante 16 la cual recordemos que había criticado duramente el tratamiento informativo que se daba a cierto caso de discriminación hacia una persona indígena, pero que en otro momento de la entrevista no duda en señalar con contundencia que

no [no le incomoda que los medios proyecten noticias culturales de su grupo étnico o de otros indígenas], porque me identifico. Es padre cuando lo publican, un evento en la Macroplaza o a tal universidad o municipio. Me emociona mucho (informante 16).

¿De qué nos está hablando esta ambivalencia? Es claro que no podemos relacionar la postura crítica del informante hacia el tratamiento mediático de sus culturas como un rechazo hacia su propia identidad étnica, pues solo en un caso de los 29 analizados una posición crítica podría ser vinculada a una actitud de rechazo hacia la propia identidad (el caso que ya señalamos de la informante 1). Más bien al contrario, los que mostraron cierto disgusto hacia el tratamiento que recibe la información relativa a la población indígena son los más activos en la defensa de los derechos de este colectivo y los que han mostrado una identidad más fortalecida. También este es el caso de las dos informantes con las que cerramos este artículo, dos personas que anteponen la intensa emoción que supone para ellas verse reflejadas e identificarse con su concreto grupo de referencia (étnico en el caso de la informante 14 e indígena en el caso de nuestra informante de etnia mixe) a la imagen "externa" o la representación que los medios arrojan de ellos mismos.

En definitiva, más allá de cómo son percibidos los contenidos o las representaciones del propio grupo de referencia, se impone un sentido de pertenencia que provoca una serie de intensas reacciones emocionales de carácter positivo cuando hay un reconocimiento efectivo en la imagen proyectada y de carácter negativo cuando se percibe la imagen como deformada y muy alejada de lo que uno siente que realmente es.

\section{Conclusión}

93 Con este artículo nos propusimos analizar de qué manera son interpretadas y significadas por los estudiantes indígenas de Educación Media Superior y Superior emigrados a Monterrey las representaciones que los medios de comunicación elaboran de sus diversas culturas originarias. Decidimos presentar los resultados atendiendo separadamente a la presencia y valoración otorgada a las lenguas indígenas reproducidas en estos medios y, por otra parte, a la significación de las imágenes y mensajes emitidos que los entrevistados consideran que representan a sus propias culturas. Asimismo, decidimos, al igual que en un trabajo anterior y al que este artículo da continuidad, analizar separadamente las respuestas dadas por los estudiantes de preparatoria de aquellos que estudian o estudiaron en la universidad (pues consideramos que, por cuestiones de edad, suponen dos momentos de desarrollo personal e identitario muy diferenciado).

En lo que se refiere al consumo de lenguas indígenas presentes en los medios de comunicación por parte de los preparatorianos entrevistados, encontramos que ninguno de ellos dicen escuchar sus respectivos idiomas en estos medios, lo cual correlaciona claramente con un fenómeno que ya conocemos por estudios anteriores (Olvera, Doncel y Muñiz 2014): el ocultamiento o la resistencia a la aceptación de la propia identidad étnica entre adolescentes indígenas estudiantes de preparatoria. Sin embargo, parece que en los niveles superiores de educación se da un desarrollo positivo y cierto proceso de visibilización de la identidad étnica, pues encontramos entre los estudiantes 
universitarios que muchos ya empiezan a escuchar sus idiomas en diversos medios de comunicación.

Así parece que, ante un panorama caracterizado por la tensión entre fuerzas globalizadoras centrífugas y tendentes a la disolución de identidades étnicas y fuerzas centrípetas (posiblemente reacción de las primeras) reforzadoras de estas identidades, el mayor nivel educativo alcanzado aparece como un claro factor que actúa positivamente en la dirección de las fuerzas fortalecedoras de la identidad. Aquí debemos introducir un matiz importante: del discurso de los informantes no se deduce una identidad esencialista ni retrotraída al pasado tradicional, sino que, como exponía Hall, la identidad aparece como "siempre en proceso", resultando una solución de continuidad que reincorpora elementos originarios pero integrándolos a la nueva experiencia vital. Esta experiencia, implica un aprendizaje, un modo de vida urbano y una convivencia con el mestizo, tradicionalmente percibido como extraño pero cada vez más desidealizado.

La duda que nos depara el futuro es hasta qué punto estos procesos de intersección que, a decir de Grimson, son todos los procesos culturales, serán capaces de transformar las consideradas tradicionales identidades étnicas, así como el modo en que estas serán reinventadas y adaptadas a una nueva realidad, y cómo sobrevivirán a las cada vez más frecuentes situaciones de contacto intertétnico. Si Barth deposita precisamente en estas situaciones de contacto la garantía que asegura la pervivencia de las etnias, cabe preguntarse qué sucederá cuando estas situaciones sean tan frecuentes (y a niveles más individuales que colectivos) que no puedan ya ser vividas como tales y, por tanto, el sujeto cuestione su etnicidad como categoría de adscripción. Lo que es claro es que, como señalábamos en el cuerpo del artículo, el futuro de la configuración étnica a nivel tanto de intersubjetividad como de práctica social está en las manos de los jóvenes indígenas $\mathrm{y}$, más aún, de los que alcancen mayores logros educativos, pues representan la punta de lanza en el proceso de cambio social, cultural e identitario al que se refería Burke. La razón es clara: son ellos los que se encuentran más expuestos al cambio, pues transitan los límites de mundos socioculturales en contacto cotidiano, mientras que estos límites tradicionalmente les estaban, en muchos sentidos, vetados a sus ancestros.

En este sentido, son aún más destacables los casos en los que los propios sujetos se convierten en actores y promotores de sus propias culturas, aquellos universitarios que no solo consumen medios en su idioma, sino que son creadores de sus propios productos mediáticos, difundiendo así sus idiomas y su cultura en hibridación con lo aprendido en la sociedad de acogida. Los medios más frecuentes a través de los cuales estos estudiantes pasan de ser consumidores a productores son la radio y las redes sociales. En este sentido, parece que correlaciona positivamente el activismo social de ciertos entrevistados con un fuerte y desarrollado sentido de la identidad. Por otra parte, también hemos encontrado que aquellos que tienen una ocupación más vinculada con el desarrollo de las propias culturas indígenas, como algunas maestras de educación intercultural, también muestran un consumo y una conciencia más desarrollada que el resto de entrevistados. Así, detectamos en estos casos una autoconciencia de la problemática de la que forman parte que va más allá de la mera identificación, pues se relaciona con el conocimiento de unas circunstancias históricas específicas. Es decir, lo que entra en juego aquí no es únicamente una concepción de "lo que soy", sino de "lo que pasa" o "lo que nos pasa".

Esto nos permite tener razones para un mayor optimismo que autores como Friedlander, que consideran la situación de pobreza y desprestigio social del indígena como algo inherente a su propia condición de indígena. Lo que vislumbramos con casos como estos 
(los que hemos encontrado en nuestro estudio y tantos otros que cada vez más se empiezan a analizar en la literatura antropológica) es un proceso incipiente de empoderamiento, tanto a través del acceso a la educación superior como a los medios de comunicación de masas. La posible relación entre nivel educativo y activismo mediático, por llamarlo de algún modo, es algo que debería ser analizado en otra parte. Pero lo que es claro es que existe una tendencia creciente a la reivindicación de lo propio, para lo cual es de vital importancia, como expuso Nahmad, la apropiación de los medios y la posibilidad de recrear la propia imagen, no dejando esto en manos ajenas. En estos nuevos espacios mediáticos también se ha manifestado la importancia esencial de la reproducción lingüística (recordemos el título del programa de radio al que se refería nuestro informante: "La Voz de las Huastecas"; en clara alusión al plurilingüismo de la región), lo cual entronca con el reclamo de autores como Uribe-Jongbloed.

Volviendo a los resultados empíricos de nuestra investigación, otra idea destacable es que incluso la mayor parte de los universitarios que no escuchan medios en su idioma dejan de hacerlo por criticismo y desde una posición de cierta fortaleza identitaria y conciencia cuestionadora. Solo unos pocos dejan de consumirlo por una desvinculación real con su cultura y comunidad originarias. Asimismo, es importante señalar que estos entrevistados universitarios han mostrado diferentes niveles de identificación étnica (comunitaria, étnica, regional, nacional, indígena...), pareciendo que a medida que el sujeto adquiere más conciencia y despliega una actitud más activa en la lucha de los derechos de estas minorías, la identificación se amplía progresivamente hasta cristalizar en una identidad indígena panamericana que va mucho más allá de su propia comunidad, etnia o región de referencia.

Llaman la atención algunas citas de nuestros informantes en las que la identidad indígena se plantea por oposición a la identidad nacional construida, oficial y artificialmente, desde las instancias gubernamentales y a través de agentes socializadores como la escuela o los medios de comunicación de masas. Esto nos permite reflexionar respecto del problema de la "angustia de lo incompleto" que plantea Appadurai como una posición de las mayorías hacia las minorías. En este sentido nos preguntamos acerca de la posibilidad de invertir la dirección de esta relación, pues estos sentimientos cuestionadores o burlones de la propia mexicanidad, expresados por nuestros entrevistados más activos políticamente en la defensa de los derechos indígenas, nos permiten apuntar hacia la sensación de que es la representación e interiorización de la identidad nacional "oficial" la que "contamina" su identidad étnica o, incluso, su adscripción como indígena americano.

101 En lo que se refiere al consumo de productos mediáticos que los entrevistados consideran que representan a sus culturas, vemos que entre los preparatorianos entrevistados sí son consumidos por un número significativo (aunque siguen siendo mayoría los que no los consumen). Especialmente ilustrativa nos pareció el caso de la preparatoriana ya egresada y con una edad ligeramente superior a la media, cuya narración creemos que representa el paso intermedio entre el autoocultamiento y la reivindicación identitaria, pues, por una parte, muestra una confusión cognitiva respecto a qué supone que es ser indígena, mientras que, por otra parte, hace explícito su sentimiento de orgullo por el hecho de ser indígena.

102 En la misma línea que lo encontrado con las preguntas referidas a la lengua, también entre los universitarios volvemos a detectar un sentido de la identidad étnica mucho más desarrollado que en el caso de los preparatorianos. Absolutamente todos los 
universitarios entrevistados afirmaron consumir productos mediáticos relacionados con las expresiones y prácticas culturales consideradas propias de su grupo étnico. Incluso, algunos de ellos, mostraron, explícita o implícitamente, una identidad multiétnica y una cosmovisión propias que denotan una importante elaboración cognitiva previa. Es decir, de nuevo podemos empezar a hablar en estos casos de una identidad con conciencia.

En cuanto a la valoración que nuestros entrevistados dan a la reproducción de sus culturas en los medios de comunicación, la mayor parte considera que es importante y que es positivo. Los contenidos que mencionan espontáneamente a este respecto son básicamente dos: los que se refieren a la difusión de sus costumbres y tradiciones y los que suponen mostrar el éxito de niños y niñas indígenas en diversos concursos relacionados con el desempeño educativo. Es decir, en estos casos la proyección de contenidos que se refieren a la riqueza cultural de los pueblos originarios es interpretada como una forma de reconocimiento de lo propio, lo cual provoca un sentimiento que en ocasiones puede llevar al sujeto a cuestionar o a relativizar una identidad nacional percibida en cierto modo como ajena. Pero también en este grupo de respuestas encontramos informantes que parecen haber asimilado en alto grado los valores dominantes, y asumido su inferior posición estructural, como aquel entrevistado que considera un "ascenso" el hecho de que sus culturas merezcan ser reproducidos en los medios de comunicación dominantes. En suma, creemos que estas posiciones opuestas ejemplifican perfectamente el conflicto o tensión de identidades móviles que plantea Appadurai entre las identidades de origen, las de residencia y las de aspiración.

Aunque fueron cuantitativamente muchos menos los entrevistados que valoraron negativamente la proyección de productos mediáticos que reflejan sus culturas, estos pocos mostraron mayor análisis crítico ante el fenómeno en sí. De hecho, lejos de suponer que esta valoración negativa correlacione con una negación de la propia identidad (solo se dio esta correlación en el caso de una estudiante en edad adolescente), lo cierto es que fueron estos estudiantes más críticos los que presentaban, en muchos sentidos, una identidad étnica más fortalecida. El discurso crítico de estos pocos entrevistados, discurso centrado en la función estigmatizadora de los medios de comunicación, giró en torno a: la consideración de que los mensajes transmitidos son vejatorios y discriminatorios hacia el indígena; la consideración de que estos mensajes contribuyen a la victimización del indígena; la consideración de que estos mensajes estereotipan; la consideración de que estos mensajes emiten una imagen del indígena folclorizadora y muy alejada del moderno indígena inserto en la era de la globalización.

Consideramos que este último aspecto, el de la folclorización del indígena, reviste especial relevancia para el debate sobre las identidades y el papel de los medios de comunicación. Si retomamos nuevamente a Hall y su idea de que las identidades se constituyen dentro de la representación y que "se relacionan tanto con la invención de la tradición como con la tradición misma” (Hall 2011, p.18), es fácil imaginar que uno de los principales conflictos que debe afrontar el joven indígena emigrado a la ciudad es su integración al mundo moderno globalizado frente a las expectativas generadas, a través de los medios de comunicación, para su conservación y cosificación como garante y custodio de una tradición entendida en el plano simbólico como esencia de mexicanidad, pero despreciada en el plano material cotidianamente por ser considerada sinónimo de atraso social y cultural (Doncel 2013).

Por último, también hubo un grupo de entrevistados que se mostraron, respecto a la valoración de la representación mediática de sus culturas, o bien indiferentes o bien 
ambivalentes. En los que ofrecieron respuestas más ambiguas encontramos un discurso que consideramos que contiene la complejidad de la problemática en la contradicción y síntesis dentro de un mismo sujeto. Así, hemos visto cómo coexiste en el mundo de significados de la misma persona una interpretación compleja de la función de los medios de comunicación y de los mensajes que transmite: si bien en ocasiones son percibidos como generadores de estereotipos a través, por ejemplo, de la victimización del indígena, también se aprecia el poder que tienen para dar a conocer, denunciar ciertas problemáticas muy reales $\mathrm{y}$, en definitiva, generar conciencia; $\mathrm{y}$, finalmente, también son percibidos como plataforma para que el propio indígena le dé contenido y exprese su propio ser.

\section{Fuentes primarias}

Informante clave 1. Presidente de la Federación de Estudiantes Indígenas de la Universidad Autónoma de Nuevo León.

Informante 1. Mujer. Tének. 17 años. Estudiante de preparatoria.

Informante 2. Mujer. Tének. 20 años. Estudiante de preparatoria.

Informante 3. Hombre. Náhuatl. 18 años. Estudiante de preparatoria.

Informante 4. Mujer. 17 años. Náhuatl. Estudiante de preparatoria.

Informante 5. Mujer. 20 años. Tének. Egresada de preparatoria.

Informante 6. Mujer. 18 años. Sin dato. Estudiante de preparatoria.

Informante 7. Mujer. 15 años. Náhuatl. Estudiante de preparatoria.

Informante 8. Hombre. 15 años. Náhuatl. Estudiante de preparatoria.

Informante 9. Mujer. 23 años. Sin dato. Egresada de preparatoria.

Informante 10. Hombre. 24 años. Náhuatl. Licenciado en Ingeniería Civil. Estudiante de Derecho.

Informante 11. Mujer. 27 años. Tének. Licenciada en Pedagogía.

Informante 12. Hombre. 42 años. Náhuatl. Licenciado en Derecho.

Informante 13. Mujer. 30 años. Tének. Licenciada en Pedagogía.

Informante 14. Mujer. 26 años. Tének. Licenciada en Psicología. Estudiante de Maestría en Educación.

Informante 15. Mujer. 19 años. Tének. Estudiante de Pedagogía.

Informante 16. Mujer. 22 años. Mixe. Estudiante de Ingeniería en Sistemas de Administración.

Informante 17. Hombre. 24 años. Náhuatl. Estudiante de Desarrollo de Negocios

Informante 18. Mujer. 24 años. Náhuatl. Estudiante de Trabajo Social y Desarrollo Humano.

Informante 19. Mujer. 24 años. Tzotzil. Estudiante de Administración de Empresas.

Informante 20. Mujer. 22 años. Náhuatl. Estudiante de Pedagogía.

Informante 21. Mujer. 19 años. Náhuatl. Estudiante de Pedagogía.

Informante 22. Hombre. 29 años. Náhuatl. Licenciado en Derecho y Criminología. Estudiante de Maestría en Trabajo Social. 
Informante 23. Hombre. 36 años. Náhuatl. Licenciado en Administración de Empresas. Estudiante de Banca y Finanzas.

Informante 24. Mujer. 17 años. Náhuatl. Estudiante de Trabajo Social y Desarrollo Humano.

Informante 25. Hombre. 22 años. Tének. Estudiante de Derecho.

Informante 26. Hombre. 23 años. Mixteco. Estudiante de Contaduría Pública y Administración.

Informante 27. Mujer. 23 años. Mazateca. Estudiante de Enfermería y Obstetricia.

Informante 28. Hombre. 49 años. Náhuatl. Estudiante trunco de Pedagogía.

Informante 29. Mujer. 26 años. Totonaca. Estudiante trunca de Hotelería y Turismo.

\section{BIBLIOGRAPHY}

Ampuero, J. (2013). Construcción de la identidad y la alteridad en la Universidad Indígena Guaraní y de Pueblos de Tierras Bajas “Apiaguaiki Tüpa” en Bolivia. Revista Electrónica Interuniversitaria de Formación de Profesorado, 16 (3), 95-116.

Appadurai, A. (2007). El rechazo de las minorías. Ensayo sobre la geografía de la furia. Barcelona: Tusquets.

Barth, F. (Comp.) (1976). Los grupos étnicos y sus fronteras. La organización social de las diferencias culturales. México: FCE.

Bauman, Z. (2011). De peregrino a turista, o una breve historia de la identidad. En S. Hall y P. de Gay (Comps.), Cuestiones de identidad cultural. (pp. 40-68). Buenos Aires: Amorrortu.

Berry, J. W. (1980). Acculturation as varieties of adaptation. En A. Padilha (Ed.), Acculturation: Theory, models and some new findings (pp. 9-25). Boulder, CO, USA: Westview.

Bonfil, G. (1972). El concepto de indio en América: una categoría de la situación colonial. Anales de Antropología, 9, 105-125.

Burke, P. (2010). Hibridismo Cultural. Madrid: Akal

Castells, A. (2003). Cine indígena y resistencia cultural. Revista Latinoamericana de Comunicación CHASQUI, 84, 50-57.

CDI. (2006). Percepción de la imagen del indígena en México. Diagnóstico cuantitativo y cualitativo. México: CDI.

CDI. (2011). Acciones de gobierno para el desarrollo integral de los pueblos indígenas. Informe 2010. México: CDI.

Cisneros, A. (2006). Los indígenas contra la modernidad. El Cotidiano, 21 (137), 32-37.

Del Popolo, F. y Ribotta, B. (2011). Migración de jóvenes indígenas en América Latina. En F. del Popolo (Coord.), Pueblos indígenas y afrodescendientes en América Latina: Dinámicas poblacionales (pp.101-125). Río de Janeiro: ALAP-UNFPA. 
Díaz, J. (2006). Identidad, adolescencia y cultura. Jóvenes secundarios en un contexto regional, Revista Mexicana de Investigación Educativa, 11 (29), 431-457.

Dietz, G. (2010). Comentarios. En S. Durin (Coord.), Etnicidades urbanas en las Américas. Procesos de inserción, discriminación y políticas multiculturalistas. México: Publicaciones de la Casa Chata.

Doncel, J. (2011). Extranjeros en Monterrey: construcción de comunidades y de identidades ciudadanas. México: CONARTE.

Doncel, J. (2012a). Nuevos retos y formas de la labor etnográfica a partir de la reconceptualización del objeto de estudio de la antropología social. Andamios. Revista de investigación social, 9 (19), 11-30.

Doncel, J. (2012b). Símbolos identitarios y cambio de valores en la Armada. El caso de la base naval de Ferrol. Saarbrücken: EAE

Doncel, J. (2013). El indígena imaginado. Estereotipos presentes en el discurso sobre la población indígena. En C. Muñiz (Coord.), Medios de comunicación y prejuicio hacia los indígenas. México: Fontamara.

Doncel, J. (en prensa). Significaciones de mass media en preparatorianos y universitarios indígenas emigrados a Monterrey. Estudios Fronterizos.

Douglas, M. (1998). Estilos de pensar. Ensayos críticos sobre el buen gusto. Barcelona: Gedisa. Durin, S. (2010). Etnicidades urbanas en las Américas. Procesos de inserción, discriminación y políticas multiculturalistas. México: Publicaciones de la Casa Chata.

Durin, S. (2013). Servicio doméstico de planta y discriminación en el área metropolitana de Monterrey. Relaciones. Estudios de historia y sociedad, 34 (134), 93-129.

Espinosa, O. (1998). Los pueblos indígenas de la Amazonía peruana y el uso político de los medios de comunicación. América Latina Hoy, 19, 91-100.

Esteinou, J., Chávez, L. y Peniche, M. (2002). La reforma del Estado y el acceso de los pueblos indios a los medios de comunicación. Economía, Sociedad y Territorio, 3 (12), 639-673.

Fernández de Rota, J. (2005). Nacionalismo, cultura y tradición. Barcelona: Anthropos.

Flores, C. (2005). Video indígena y antropología compartida: una experiencia colaborativa con videastas maya-q'eqchi' de Guatemala. LiminaR. Estudios Sociales y Humanísticos, 3 (2), 7-20.

Foucault, M. (1968). Las palabras y las cosas. Una arqueología de las ciencias humanas. México: Siglo XXI.

Friedlander, J. (2007). Ser indio otra vez en Hueyapan. Disponible en:

http://www.publicaciones.cucsh.udg.mx/pperiod/estsoc/pdf/estsoc_07/estsoc07_221-230.pdf

García Canclini, N. (2005) Diferentes, desiguales y desconectados. Mapas de la interculturalidad. Barcelona: Gedisa.

García Domingo, R. (2015). Un estudio de la comunicación indígena en la comunidad Jivi de Ekunay. Valladolid: Universidad de Valladolid.

Geertz, C. (2005). La interpretación de las culturas. Barcelona: Gedisa.

Giddens, A. (1993). Las nuevas reglas del método sociológico. Crítica positiva de las sociologías interpretativas. Buenos Aires: Amorrortu.

Grimson, A. (2011). Los límites de la cultura. Crítica de las teorías de la identidad. Madrid: Siglo XXI. 
Hall, S. (2011). Introducción: ¿quién necesita “identidad”? En S. Hall y P. de Gay (Comps.), Cuestiones de identidad cultural (pp. 13-39). Buenos Aires: Amorrortu.

INEGI (2010). XIII Censo de población y vivienda 2010. Tabulados básicos.

Lavaud, J. y Lestage, F. (2006) El indianismo en la América hispánica. Una nebulosa política equívoca. Política, 47, 149-169.

Mead, G. H. (1973). Espíritu, persona y sociedad. Desde el punto de vista del conductismo social. Barcelona: Paidós.

Mead, M. (1993 [1939]). Adolescencia y Cultura en Samoa. Buenos Aires: Planeta-Agostini.

Mercado, A. (2015). Medios indígenas transnacionales: el fomento del cosmopolitismo desde abajo. Comunicación y Sociedad, 23, 171-193.

Molina, V. (2010). Inserción laboral de los indígenas en la ciudad de México. En S. Durin (Coord.), Etnicidades urbanas en las Américas. Procesos de inserción, discriminación y políticas multiculturalistas. México: Publicaciones de la Casa Chata.

Moreno, F. (2012). Principios de sociolingüistica y sociología del lenguaje. Barcelona: Arial.

Moreno, R. (2010). Indígenas en la ciudad y en la lejanía. La representación diferenciada de los indígenas en el discurso periodístico (El Norte: 1988-2006). En S. Durin (Coord.), Etnicidades urbanas en las Américas. Procesos de inserción, discriminación y políticas multiculturalistas. México: Publicaciones de la Casa Chata.

Muñiz, C. (Coord.) (2013). Medios de comunicación y prejuicio hacia los indígenas. México: Fontamara. Nahmad, A. (2007). Las representaciones indígenas y la pugna por las imágenes. México y Bolivia a través del cine y el video, en Latinoamérica. Revista de Estudios Latinoamericanos, 45, 105-130.

Olvera, J., Doncel, J. y Muñiz, C. (2014). Indígenas y educación. Diagnóstico para el nivel medio superior en Nuevo León. México: U-ERRE/FENL/UANL.

Ortega y Gasset, J. (1971). Verdad y perspectiva. En J. Ortega y Gasset, El espectador. Navarra: Salvat.

Ortner, S. (1984). Theory in Anthropology since the Sixties. Comparative Studies in Society and History, 26 (1), 126-166.

Palmer, G. (2000). Lingüística cultural. Madrid: Alianza.

Pierre Bonte, M. (1996). Diccionario de Etnología y Antropología. Madrid: Akal .

Rivermar, M. (2010). Nahuas del estado de Puebla en el mercado laboral de la costa este de los Estados Unidos. En S. Durin (Coord.), Etnicidades urbanas en las Américas. Procesos de inserción, discriminación y políticas multiculturalistas. México: Publicaciones de la Casa Chata.

Sapir, E. (1929). El estado de la lingüística como ciencia. Disponible en:

http://es.scribd.com/doc/121883120/El-Estado-de-la-Linguistica-como-ciencia-Texto-Sapir Shaff, A. (1975). Lenguaje y conocimiento. México: Grijalbo.

Uribe-Jongbloed, E. (2011). Estudios de medios de comunicación en idiomas minoritarios y la comunicación para el cambio social: diálogo entre Europa y América Latina. Investigación \& Desarrollo, 19 (1), 2-25.

Vázquez-García, V. y Muñoz-Rodríguez, C. (2013). Género, etnia y violencia en Ayutla, Oaxaca. Convergencia. Revista de Ciencias Sociales, 20 (62), 135-158. 
Zamorano, G. (s.f.) Los usos del video comunitario para imaginar un Estado Plurinacional. Disponible en:

http://www.bolivianstudies.org/revista/9.1/documentos_pdf/ZamoranoGabriela42712.pdf

\section{NOTES}

1. Comisión Nacional para el desarrollo de los Pueblos Indígenas.

2. Este proyecto, dirigido por el Dr. Doncel, está aprobado y financiado por el Consejo Nacional para la Ciencia y la Tecnología (CONACyT) a través de su programa de Ciencia Básica.

3. De la complejidad e indefinición del término mestizo da buena cuenta Moreno, recuperando el trabajo de Manuel Alvar, cuando se refiere a la identificación de " 82 formas de mestizaje: de blanco e india: mestizo; de mestizo y española: castizo; de castizo y española: chamizo; de chamizo y mestiza: coyote mestizo; de blanco y negra: mulato; de coyote mestizo y mulata: ahí te estás" (Moreno, 2012, p. 70). Desde el punto de vista de Bonfil Batalla "la amplitud de la miscigenación ocurrida entre poblaciones muy diversas -entre sí y dentro de cada una de ellas(...) hace que en América todos resultemos mestizos".

4. Con este "entendemos", me refiero más al término que se emplea en el ámbito académico mexicano y no tanto en la sociedad mexicana, sociedad de la que este autor forma parte en su calidad de extranjero e inmigrante.

5. Esta problemática ya fue abordada, por ejemplo, también para el estado de Nuevo León, en la obra "Medios de comunicación y prejuicio hacia los indígenas" (Muñiz 2013)

6. En el marco de nuestro proyecto más amplio, nuestra becaria Julieta Martínez está realizando una excelente tesis cuyo principal objetivo consiste en analizar la forma en la que estos migrantes indígenas con estudios superiores se plantean el posible retorno a su comunidad. Este problema esconde uno mayor: el despoblamiento y la desintegración comunitaria con la consiguiente transformación de las identidades étnicas de este país.

7. En posteriores trabajos desarrollaremos, a partir de la técnica de la historia de vida, estos procesos de reconstrucción identitaria desde la comprensión de la línea vital de un mismo sujeto. 8. Por ejemplo, en el análisis realizado en el primer trabajo, ya mencionado, acerca de la costumbre y significación diferenciada de ir al cine. En este artículo (Doncel, en prensa), concluimos explicando cómo la costumbre o el ritual urbano de "ir al cine", en gran medida ajeno a estos estudiantes indígenas, encuentra su correlato en sus comunidades de origen con lógicas sociales y significaciones diversas. Así, la costumbre de la visualización colectiva de una pequeña pantalla de televisión es leída desde diversas dimensiones de análisis: social (por su función cohesionadora, así como por el hecho de suponer un espacio de socialización primaria), cultural (pues se asienta sobre cierto valor de lo colectivo y sobre otra forma de dimensionar los ámbitos de lo público-privado) y económica (dinamizando una práctica que se convierte en intercambio de servicios y, más adelante, en comercio con mediación pecuniaria). Se trata, en suma, del "cine" en la comunidad de origen entendido como espacio en el que también se construye la identidad comunitaria o étnica.

9. Respecto al debate entre concepto de lengua frente a dialecto, Moreno explica que las definiciones propuestas para ambos "han sido muchas y diversas" (Moreno 2012, p. 92), a lo que añade que "desde un punto de vista rigurosamente lingüístico, no existen evidencias que justifiquen la distinción entre lengua y dialecto, por lo que resulta obligado recurrir a criterios extralingüísticos, si se quiere mantener. Algunos autores, sin embargo, han evitado la diferenciación negando simplemente la existencia de los dialectos" (Moreno 2012). Pero, como se propone desde la sociolingüística y desde la antropología lingüística, no podemos obviar la importancia de estos "criterios extralingüísticos", sobre todo para comprender una determinada 
estructura de poder reflejada en el prestigio y desprestigio de ciertas lenguas que conviven en un mismo contexto social. Como escribe Fernández de Rota, "el panorama lingüístico tensional, en transformación, complejo, que nos ofrece esta época nos habla evidentemente de una jerarquía de lenguajes y de distintos niveles de poder y dominación relacionados con ellos. Las situaciones de dominio de unas sociedades sobre otras suelen venir acompañadas por la hegemonía de determinadas lenguas que sirven como vehículo de organización y de administración del poder" (Fernández de Rota 2005, p. 91).

10. Cabe mencionar aquí que nuestra pretensión de alcanzar esta descripción densa se limita a esta concepción del trabajo del etnógrafo como un trabajo de profundización y construcción de los significados dados por los actores sociales, pero no pretendemos, en esta fase de la investigación, dar cuenta de la complejidad del contexto social y cultural en que se mueven estos actores (lo que supondría una auténtica descripción densa). Recordemos que aquí estamos iniciando un largo proceso de investigación, por lo que esperamos alcanzar los frutos de la descripción densa en toda la extensión del término tras el trabajo de campo etnográfico centrado en los otros agentes socializadores a los que nos referíamos al principio de este trabajo: familia, comunidad, escuela y ámbito laboral (pues son objetivos que exigen la necesaria convivencia de técnicas metodológicas - como la historia de vida, la entrevista y la observación participantepara lograr este tipo de descripción).

11. Recordemos la justificación del uso del término "dialecto" en ciertas entrevistas, explicada detalladamente en la introducción de este artículo.

12. En posteriores trabajos desarrollaremos la problemática de la construcción de la identidad atendiendo a los círculos concéntricos de identidad comunitaria, étnica, regional, indígena y nacional. Estos círculos identitarios, contenidos unos dentro de otros, fueron explicados para entender los procesos de construcción de identidades militares y marineras en un trabajo anterior sobre la Armada Española y sus símbolos identitarios (Doncel 2012b).

13. Acerca del problema del trabajo doméstico de las migrantes indígenas ha escrito profusamente la Dra. Séverine Durin, como es el caso de su estudio acerca de la explotación laboral de las empleadas domésticas en la Zona Metropolitana de Monterrey (Durin 2013).

14. No planteamos aquí la problemática, trabajada desde Margaret Mead (1993 [1939]) hasta nuestros días (del Popolo y Ribotta 2011), de la conceptualización diferenciada según el contexto cultural de lo que se entiende por edad adolescente (edad cuya existencia es negada en ciertas sociedades, según Mead). No obstante, no está de más señalar aquí que el emigrante indígena debe responder, en su tránsito de la comunidad de origen a la sociedad de acogida, a expectativas sociales muy diferentes en lo que se refiere a su edad.

15. El problema de la moralidad se presenta de manera contundente a la hora de juzgar desde la sociedad mestiza las prácticas incestuosas en muchas comunidades indígenas (Vázquez-García y Muñoz-Rodríguez 2013). Estas prácticas, más o menos extendidas pero innegablemente reales, como hemos podido conocer a través de nuestro trabajo de campo, constituyen un tabú esencial desde la dominante moral católica, lo que hace de ellas un objeto de estudio extremadamente escurridizo. Sin embargo, esperamos, en posteriores etapas de nuestra investigación, poder ahondar en el análisis de estas prácticas, expresión de una radical endogamia y, en último término, factor explicativo del intenso sentido de pertenencia que marca las lógicas de interacción social de la población indígena tanto intragrupal como intergrupal. 


\section{ABSTRACTS}

The recent but intense flow of indigenous migration to the industrial Mexican state of Nuevo Leon sets out a double challenge: social and academic. Here we introduce the results of a vast investigation in which we pretend to analyze the process of identity reconfiguration that these indigenous immigrants undergo, specifically those who manage to overcome the stigma impose by their ethnicity, reaching higher levels of education (secondary and higher education). In this article we analyze the role of the mass media understood as an essential socializing agent and, consequently, leading factor in the process of construction of ethnic identities. Thus, we try to understand how the mass media representations of various Mexican indigenous cultures are interpreted and signified by the protagonists of our investigation project. After establishing the theoretical bases and making a brief review of some of the empirical data, we provide the results of an extensive field work (29 interviews), analyzing the way in which these students consume and appreciate the presence of their mother tongue in the mass media (understanding language as the basis of culture) and how they value and signify the way that the media they consume show their own cultures to the audience. Transversely to this analysis we begin to establish the impact that the media coverage has on the construction or reconstruction of their own ethnic identities.

El reciente pero intenso flujo de migración indígena al industrial estado mexicano de Nuevo León plantea un doble reto: social y académico. Aquí presentamos los resultados de una investigación mayor con la que pretendemos analizar el proceso de reconfiguración identitaria que viven estos inmigrantes indígenas; específicamente aquellos que logran superar el estigma que su condición étnica les impone alcanzando los niveles superiores de educación (Educación Media Superior y Superior). Concretamente, en este artículo analizamos el papel de los medios masivos de comunicación entendidos como esencial agente socializador y, en consecuencia, factor destacado en el proceso de construcción de las identidades étnicas. De este modo, tratamos aquí de entender cómo son interpretadas y significadas por los protagonistas de nuestra investigación las representaciones que los medios de comunicación elaboran de las expresiones y prácticas culturales de los diversos pueblos indígenas presentes en el actual territorio mexicano. Tras establecer las bases teóricas y hacer un breve repaso por algunos de los antecedentes empíricos, ofrecemos los resultados de un amplio trabajo de campo (veintinueve entrevistas semidirigidas), analizando el modo en el que estos estudiantes consumen y valoran la presencia de sus lenguas maternas en los medios de comunicación (entendida la lengua como eje estructurador de la cultura) y de cómo valoran y significan la forma en la que los medios que consumen muestran a la audiencia su propios rasgos culturales. Trasversalmente a este análisis pretendemos comenzar a establecer el impacto que esta proyección mediática tiene sobre la construcción, o reconstrucción, de sus propias identidades étnicas. 
INDEX

Keywords: Ethnic identity, mass media, high and university education, language, culture.

Palabras claves: Identidad étnica, medios de comunicación de masas, Educación Media Superior y Superior, lengua, cultura

\section{AUTHOR}

\section{JUAN ANTONIO DONCEL DE LA COLINA}

Centro de Estudios Interculturales del Noreste/Universidad Regiomontana, México.

Correo electrónico: jdoncel@u-erre.mx 